\title{
From meteorological to hydrological drought using standardised indicators
}

\author{
Lucy J. Barker ${ }^{1}$, Jamie Hannaford ${ }^{1}$, Andrew Chiverton ${ }^{1, a}$, and Cecilia Svensson ${ }^{1}$ \\ ${ }^{1}$ Centre for Ecology \& Hydrology, Wallingford, UK \\ ${ }^{a}$ now at: Environment Agency, Exeter, UK \\ Correspondence to: Lucy J. Barker (lucybar@ceh.ac.uk)
}

Received: 6 November 2015 - Published in Hydrol. Earth Syst. Sci. Discuss.: 10 December 2015

Revised: 15 April 2016 - Accepted: 3 May 2016 - Published: 24 June 2016

\begin{abstract}
Drought monitoring and early warning (M \& EW) systems are a crucial component of drought preparedness. M \& EW systems typically make use of drought indicators such as the Standardised Precipitation Index (SPI), but such indicators are not widely used in the UK. More generally, such tools have not been well developed for hydrological (i.e. streamflow) drought. To fill these research gaps, this paper characterises meteorological and hydrological droughts, and the propagation from one to the other, using the SPI and the related Standardised Streamflow Index (SSI), with the objective of improving understanding of the drought hazard in the UK. SPI and SSI time series were calculated for 121 near-natural catchments in the UK for accumulation periods of 1-24 months. From these time series, drought events were identified and for each event, the duration and severity were calculated. The relationship between meteorological and hydrological drought was examined by cross-correlating the 1-month SSI with various SPI accumulation periods. Finally, the influence of climate and catchment properties on the hydrological drought characteristics and propagation was investigated. Results showed that at short accumulation periods meteorological drought characteristics showed little spatial variability, whilst hydrological drought characteristics showed fewer but longer and more severe droughts in the south and east than in the north and west of the UK. Propagation characteristics showed a similar spatial pattern with catchments underlain by productive aquifers, mostly in the south and east, having longer SPI accumulation periods strongly correlated with the 1-month SSI. For catchments in the north and west of the UK, which typically have little catchment storage, standard-period average annual rainfall was strongly correlated with hydrological drought and
\end{abstract}

propagation characteristics. However, in the south and east, catchment properties describing storage (such as base flow index, the percentage of highly productive fractured rock and typical soil wetness) were more influential on hydrological drought characteristics. This knowledge forms a basis for more informed application of standardised indicators in the UK in the future, which could aid in the development of improved M \& EW systems. Given the lack of studies applying standardised indicators to hydrological droughts, and the diversity of catchment types encompassed here, the findings could prove valuable for enhancing the hydrological aspects of drought M \& EW systems in both the UK and elsewhere.

\section{Introduction}

Drought is widely recognised as a complex, multifaceted phenomenon (e.g. Van Loon, 2015). Unlike many other natural hazards, drought develops slowly, making it difficult to pinpoint the onset and termination of an event. Fundamentally, a drought is a deficit in the expected available water in a given hydrological system (Sheffield and Wood, 2011). Since Wilhite and Glantz (1985), drought has popularly been classified into various types (e.g. meteorological, hydrological, agricultural, environmental and socio-economic). The drought type generally reflects the compartment of the hydrological cycle or sector of human activity that is affected; deficits typically propagate through the hydrological cycle, impacting different ecosystems and human activities accordingly.

The desire to quantitatively identify and analyse drought duration, severity, onset and termination has led to the devel- 
opment of drought indicators. Lloyd-Hughes (2014) counted over 100 drought indicators in the literature, this proliferation reflecting the complexity of the subject matter. It has been argued that indicators should be chosen according to the type of drought in question; for example, meteorological indicators should not be used in isolation to characterise hydrological drought due to the non-linear responses of terrestrial processes to climate inputs (Van Loon and Van Lanen 2012; Van Lanen et al., 2013).

One of the primary uses of drought indicators is in monitoring and early warning (M\&EW), a crucial part of drought preparedness (Bachmair et al., 2016). Little can be done to prevent a meteorological drought from occurring, but actions can be taken to prevent or mitigate the impact of a hydrological drought. An effective drought $\mathrm{M} \& \mathrm{EW}$ system is the foundation of a proactive management strategy, triggering planned actions and responses (Wilhite et al., 2000). There are numerous examples of drought M\&EW systems globally, for example, the US Drought Monitor (http://droughtmonitor.unl.edu/Home.aspx) and the European Drought Observatory (http://edo.jrc.ec.europa.eu). However, comparatively few drought M \& EW systems incorporate hydrological variables such as streamflow; the US Drought Monitor is one such example, while others rely on runoff outputs from large-scale hydrological models (e.g. the Flood and Drought Monitors for Africa and Latin America; http://stream.princeton.edu/). In many national/regionalscale drought M\&EW systems, the emphasis is typically placed on the meteorological and/or agricultural drought hazard. As such, hydrological aspects are often less sophisticated, as discussed in a recent study that combined a literature review with a survey of 33 regional, national and global drought M \& EW providers (Bachmair et al., 2016).

The Standardised Precipitation Index (SPI; McKee et al., 1993) is one of the most widely used drought indicators. It allows consistent comparison across both time and space as well as providing the flexibility to assess precipitation deficits over user-defined accumulation periods. The SPI also gives an indication of the severity and probability of the occurrence of a drought, with increasingly negative values indicating a more severe, yet less likely, drought (Lloyd-Hughes and Saunders, 2002). Despite the advantages and flexibilities of the SPI, there are known deficiencies. The choice of an appropriate probability distribution is still under investigation in the literature (e.g. Stagge et al., 2015; Svensson et al., $2015 \mathrm{~b}$ ) and the fitting of a probability distribution function to data with a high proportion of zeros can be problematic (Wu et al., 2007). It has also been noted that as the SPI accumulation period increases, the spatial behaviour of the index becomes more fragmented, making it more difficult to identify regions with similar patterns of drought evolution (VicenteSerrano, 2006). Notwithstanding these deficiencies, the relative simplicity of calculation, comparability and flexibility of the SPI have led to an endorsement by the World Meteorological Organization as the indicator of choice for monitor- ing meteorological drought (Hayes et al., 2011). The use of precipitation alone does not take evaporative demand into account, which may result in drought severity being underestimated in regions or seasons with high levels of evapotranspiration. This led to the development of the Standardised Evapotranspiration Index (SPEI; Vicente-Serrano et al., 2010). A growing trend in drought $\mathrm{M} \& \mathrm{EW}$ research is the application of the same standardisation principles to other hydrological data types (soil moisture, streamflow, groundwater etc.), producing a family of standardised indices for all compartments of the hydrological cycle (Bachmair et al., 2016).

In the UK, there is no nationwide, drought-orientated M \& EW system in place. Regular hydrological reporting, published by the National Hydrological Monitoring Programme in monthly Hydrological Summaries (http://nrfa. ceh.ac.uk/nhmp), uses simple rank-based approaches to place current hydrological conditions in their historical context. Although it is a valuable resource, it is not used for drought planning and does not trigger actions in drought plans. Drought M \& EW is carried out individually by regulators (such as the Environment Agency in England, who produce monthly water situation reports; Environment Agency, 2016) and water companies, who also typically use simple rank-based indicators to examine drought status according to their own drought plans (e.g. Thames Water; Thames Water, 2013). While there is already very effective consultation between different stakeholders in drought planning, there are inevitably differences in interpretation and communication of droughts. There is a recognised need to develop more consistent approaches to monitoring (Collins et al., 2015), highlighting the potential benefit of a large-scale drought M\&EW system tailored to a range of end-user needs.

The absence of a coherent drought-focused M \& EW system across the UK is, in part, due to the lack of consensus on appropriate drought indicators or drought definitions for the UK. A number of drought analyses have been applied using a range of non-standardised indicators (e.g. Marsh et al., 2007; Rahiz and New, 2012; Watts et al., 2012), but the SPI and other standardised indicators have only been used in a few research studies (e.g. Hannaford et al., 2011; Lennard et al., 2016; Folland et al., 2015). Such indicators are generally not used operationally, although the Scottish Environment Protection Agency use a variant of standardised indicators for drought M \& EW (Gosling, 2014) and Southern Water use SPI in their drought plan (Southern Water, 2013).

Recently, there has been growing interest in applying the standardised family of indicators at the national scale in the UK. A Drought Portal (https://eip.ceh.ac.uk/droughts) has been developed to visualise past meteorological drought using gridded SPI data (Tanguy et al., 2016), and a version of the Standardised Streamflow Index (SSI), for hydrological drought, has been developed (Svensson et al., 2015b). Despite these advances, a major obstacle to the development of a drought-focused M\&EW system is a lack of understanding of how meteorological deficits propagate to hydrological 
drought. Folland et al. (2015) explored propagation between meteorological, streamflow and groundwater drought using standardised indicators. However, the study focused on regional averages for a single large region in south-east England, and the authors acknowledged that there is likely to be significant spatial variability in propagation as a result of the diverse climate and geology across the UK. Several studies have demonstrated the importance of catchment properties in modulating precipitation signals in UK streamflow (Laizé and Hannah, 2010; Chiverton et al., 2015a), and this has been shown specifically for drought (Fleig et al., 2011). As such, there is a need for a fuller understanding of regional variability in drought characteristics, how this variability is affected by the propagation from meteorological to hydrological drought, and which climatic and catchment properties influence these relationships.

Many studies investigating hydrological drought characterisation and drought propagation have done so at the national, continental or global scale using modelled data (e.g. Vidal et al., 2010; Van Lanen et al., 2013), or at a smaller scale using a limited number of sites and observed data (e.g. Fleig et al., 2011; López-Moreno et al., 2013; LorenzoLacruz et al., 2013b; Haslinger et al., 2014). Furthermore, few studies have used standardised indicators for both meteorological and hydrological droughts, which enables consistent characterisation across components of the hydrological cycle (and thereby potentially forming the foundation of a more integrated drought M\&EW system). Very few observational studies have addressed the influence of climate and catchment properties on drought characteristics and propagation in a wide range of catchments demonstrating climatic and geological diversity. Studies have also tended to focus on a few characteristics representing geology or climate (e.g. Vidal et al., 2010; Lorenzo-Lacruz et al., 2013b; Haslinger et al., 2014) rather than a wide range of physiographic and land use properties, with the exception of the study by Van Loon and Laaha (2015) that used 33 catchment properties.

This study exploits the long streamflow and precipitation records held by the National River Flow Archive (NRFA) for 121 catchments. Using observed data, the utility of standardised indicators, the Standardised Precipitation Index (SPI) and the Standardised Streamflow Index (SSI), for characterising drought characteristics and propagation behaviour is assessed, specifically addressing the following key questions:

1. How do meteorological and hydrological drought characteristics vary spatially across the UK?

2. Over which timescales are meteorological and hydrological droughts related?

3. Which climatic and catchment properties influence hydrological drought characteristics and the propagation from meteorological to hydrological drought?

Addressing these questions will supplement the existing knowledge of the baseline drought hazard and propagation behaviours across the UK, in a set of catchments with diverse properties, representative of hydro-climatic and landscape variations. This knowledge is an important foundation for the development of improved drought M \& EW systems (Folland et al., 2015; Van Loon, 2015), allowing preventative measures to be implemented, resulting in reduced vulnerability and increased resilience to drought.

\section{Data}

The UK has one of the densest hydrometric networks in the world. Hydrometric data are archived and curated by the NRFA (http://nrfa.ceh.ac.uk), which holds data for around 1400 gauging stations (Dixon et al., 2013). The Benchmark catchments are a subset of these gauging stations with good hydrometric performance and near-natural flow regimes (Bradford and Marsh, 2003). It was necessary to limit the study to these catchments as major artificial influences could confound the identification of links between meteorological and hydrological drought; regulated catchments have been shown to be distinctly different in terms of hydrological drought characteristics (e.g. Lorenzo-Lacruz et al., 2013b).

The selected Benchmark catchments were required to have at least 30 years of daily streamflow records 1961-2012 and each month was required to have at least 25 days of valid observations (in order to calculate mean monthly streamflow). Two ephemeral streams were excluded from the selection, as the truncation of the flows at zero would have been unhelpful when studying drought propagation. The selection criteria resulted in 121 catchments, providing good spatial coverage of the UK and a range of catchment types (Fig. 1). The selection of Benchmark catchments used here differs slightly to other published studies (e.g. Hannaford and Marsh, 2006; Chiverton et al., 2015a) because of differing selection criteria and the ongoing evolution of the Benchmark network. The NRFA also holds catchment average monthly precipitation data for each catchment based on observed UK Met Office data (Met Office, 2001; Marsh and Hannaford, 2008). At least 30 years of catchment average monthly precipitation data were available for each catchment between 1961 and 2012. In some cases, the catchment average monthly precipitation and mean monthly streamflow period of record differed in length, but all catchments had at least 30 years of data overlapping 1961-2012. Less than $10 \%$ of catchments had a difference in record length of 5 or more years, and less than $3 \%$ of catchments had a difference in record length of 10 or more years. When data completeness was calculated from the start of the catchment average monthly precipitation and mean monthly streamflow record, the proportion of missing data for each catchment was, on average, less than $0.01 \%$ of months for precipitation data and less than $2 \%$ of months for streamflow data. 


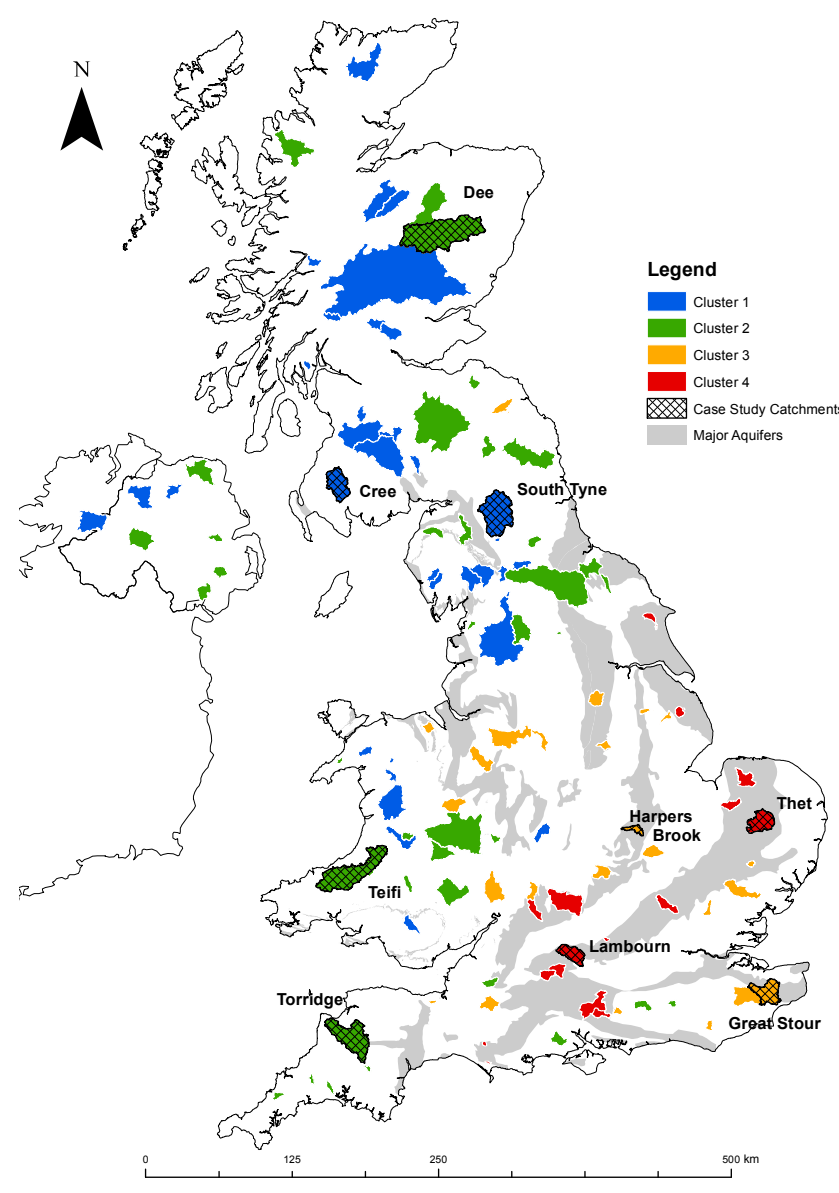

Figure 1. Location and cluster membership of UK Benchmark catchments selected for this study, including the nine case study catchments.

Catchments were clustered using a previously developed classification system (Chiverton et al., 2015a) based on the temporal dependence in daily streamflow (characterised by calculating semi-variograms), enabling calculated drought characteristics to be analysed regionally. Where the catchments overlapped with those used in Chiverton et al. (2015a), the same cluster allocations were used. The 15 catchments that did not overlap between the two studies were assigned to the cluster for which the semi-variogram was closest to the mean semi-variogram of the cluster. Figure 1 shows the distribution of clusters across the UK for the 121 selected catchments. Clusters one and two are predominantly located in the upland north and west of the UK, have steeper slopes and less storage, are less permeable and have a higher amount of precipitation than the catchments in clusters three and four which are mostly located in the south and east of the UK. Predominant soil types differ between all four clusters. Clusters one and two can also be differentiated by elevation, while clusters three and four can be differentiated by their geology (Chiverton et al., 2015a).
Nine catchments covering a range of catchment types and sizes, as well as each cluster, were selected as case study catchments (Fig. 1) to allow more detailed, catchment-scale results to be displayed in this article.

The catchment average SAAR (standard-period average annual rainfall) 1961-1990 was used as a descriptor of the precipitation climate. The SAAR values were derived from a $1 \mathrm{~km}$ gridded map based on Met Office data (Spackman, 1993). In order to investigate the influence of the physical catchment on drought propagation, catchment properties were extracted for each catchment. The selected catchment properties (Table 1) have been found in previous studies to be significant for modifying climate-streamflow associations and in determining the temporal dependence of flows (Laizé and Hannah, 2010; Chiverton et al., 2015a). Base flow index (BFI), calculated from streamflow data (Gustard et al., 1992), although not technically a catchment property, has been found to reflect catchment geology, storage and release properties and so was used as an indicator of catchment storage (Bloomfield et al., 2009; Hidsal et al., 2004; Van Loon and Laaha, 2015). Catchment properties were derived from spatial data held by the NRFA (Marsh and Hannaford, 2008), the British Geological Survey, and in some cases extracted from the Flood Estimation Handbook (FEH; Bayliss, 1999).

\section{Methods}

\subsection{Drought characteristics}

The Standardised Precipitation Index (SPI) is calculated by first aggregating precipitation data over a user-defined accumulation period (often 1, 3, 6, 12 or 24 months). A probability distribution function is then fitted to the aggregated precipitation data for each calendar end-month (of the accumulation period) individually. It is then transformed to the standard normal distribution with a mean of zero and a standard deviation of one. This transformation makes the SPI comparable over time and space. The calculated SPI value represents the number of standard deviations away from the typical accumulated precipitation (McKee et al., 1993; Guttman, 1999; Lloyd-Hughes and Saunders, 2002). For SPI calculation, a Gamma distribution is often fitted to precipitation data. Several studies have tested the most appropriate probability distribution to fit to precipitation data and in many cases found Gamma to be acceptable (e.g. Guttman, 1999; Stagge et al., 2015). The Standardised Streamflow Index (SSI) uses the same principle as the SPI, aggregating streamflow data over the given accumulation periods (Vicente-Serrano et al., 2012b; Lorenzo-Lacruz et al., 2013a). In contrast to precipitation and SPI calculation, there is no widely adopted probability distribution function fitted to streamflow data for SSI calculation, and previously, numerous probability distribution functions have been used (e.g. Vicente-Serrano et al., 2012a). Here, we fit the Tweedie 
distribution, which has been shown to fit the same catchments well (Svensson et al., 2015b), for both catchment average monthly precipitation and mean monthly streamflow. The Tweedie distribution is a flexible three-parameter distribution that has a lower bound at zero (Tweedie, 1981; Jørgensen, 1987). The "SCI" package for R (Gudmundsson and Stagge, 2014) was used to calculate SPI and SSI for the period 1961-2012 and accumulation periods of 124 months. A new function enabled the parameter estimation in the "tweedie" package for R (Dunn, 2014) to be called within the SCI package (Svensson et al., 2015b). Accumulation periods are denoted as follows: SPI-x and SSI-x, for example, SPI-6 and SSI-3 correspond to a 6-month precipitation accumulation period and a 3-month streamflow accumulation period, respectively.

Drought events were defined as periods where indicator values were continuously negative with at least 1 month in the negative series reaching a given threshold (McKee et al., 1993; Vidal et al., 2010). Thresholds of -1 (moderate drought), -1.5 (severe drought) and -2 (extreme drought; Lloyd-Hughes and Saunders, 2002) were used to identify drought events. The total number of events was calculated for each catchment, accumulation period and threshold, in addition to the mean, median and maximum event duration and severity. The duration of each individual event was calculated for the given catchment at a monthly resolution. The severity was calculated by summing the SPI/SSI values across all constituent months of each identified event in each catchment (Vidal et al., 2010) and as such has no units.

Missing catchment average monthly precipitation/mean monthly streamflow data would mean that no SPI or SSI value was calculated, potentially affecting duration/severity characteristics for some events. However, visual inspection of the data confirmed that for major UK drought events (Marsh et al., 2007), the impact of missing data was minimal and isolated to only a few catchments for streamflow data, and there were no missing precipitation data for major events. This and the low proportion of missing data in the data sets as a whole (Sect. 2) suggest the incidental months of missing data are localised and unlikely to have had a significant impact on the extracted drought characteristics.

\subsection{Drought propagation}

Streamflow, and so the SSI, integrates catchment-scale hydrogeological processes. As such, a comparison with the SPI provides an indication of the time taken for precipitation deficits to propagate through the hydrological cycle to streamflow deficits. SPI accumulation periods of 124 months and SSI-1 time series were cross-correlated using the Pearson correlation coefficient to analyse the most appropriate accumulation period of SPI to characterise to SSI1. The 1-month SSI also provides a good description of low flows, similar to the 30-day mean flow, which is often used in studies of annual minimum flows (e.g. Gustard et al., 1992).
The SPI accumulation period with the strongest correlation with SSI-1 was denoted SPI- $n$ and was used as an indicator for drought propagation. Where SSI-1 was most strongly correlated with short SPI accumulation periods, the propagation time is also short, and vice versa. To determine whether there is a lag between the SPI (accumulation periods of 124 months) and SSI-1, cross-correlations were calculated for SSI-1 series which were lagged by 0 to 6 months after the SPI series. In this case, the SPI accumulation period with the strongest correlation with SSI-1 was denoted as the lagged SPI- $n$.

Independence of data is a requirement for many statistical analyses. However, because of temporal dependence, or autocorrelation, in the SSI-1 and in all the series of SPI accumulation periods exceeding 1 month, data are not independent. Correlations between two autocorrelated time series have fewer effective degrees of freedom than is assumed in a standard significance test. As such, using a standard significance test can result in an increased chance of concluding correlations are statistically significant (i.e. an increased rate of Type 1 error; Pyper and Peterman, 1998). In order to address and control Type 1 error rates, the "modified Chelton" method outlined in Pyper and Peterman (1998) was adapted to account for missing data, and used for calculating the effective degrees of freedom for a given data series. Details of the modified Chelton method are provided in the Supplement (Sect. S1).

\subsection{Links with climate and catchment properties}

Hydrological drought characteristics were plotted against SAAR and the corresponding correlation coefficients calculated. Spearman's correlation was used because of the nonlinear relationships between the hydrological drought characteristics and SAAR. Clusters one and two were grouped together because of their location in the windward mountainous north and west of the country and clusters three and four were grouped together because of their location in the sheltered lowland south-east. Spearman's correlations were also used to quantify the relationship between the hydrological drought characteristics and catchment properties described in Table 1.

\section{Results}

\subsection{Drought characteristics}

For each accumulation period and catchment, drought events were identified using thresholds of $-1,-1.5$ and -2 (moderate, severe and extreme drought, respectively). For both SPI and SSI, unsurprisingly, more drought events were identified at shorter accumulation periods and thresholds closest to zero. As the accumulation period lengthens and the threshold moves away from zero, the number of events decreases, duration lengthens and severity worsens (Table 2). Spatial 
Table 1. Summary of catchment properties used (after Chiverton et al., 2015a).

\begin{tabular}{|c|c|c|c|}
\hline Catchment property & Abbreviation & Units & Description \\
\hline Altitude & Alt & $\mathrm{m}$ & Altitude of the gauging station to the nearest datum ${ }^{\mathrm{a}}$ (derived using IHDTM $^{\mathrm{b}}$ ). \\
\hline Elevation 10 & Elev-10 & $\mathrm{m}$ & Height above the datum ${ }^{\mathrm{a}}$ below which $10 \%$ of the catchment lies (derived using IHDTM $^{\mathrm{b}}$ ). \\
\hline Elevation 50 & Elev-50 & $\mathrm{m}$ & As above but for $50 \%$. \\
\hline Elevation 90 & Elev-90 & $\mathrm{m}$ & As above but for $90 \%$. \\
\hline Elevation max & Elev-max & $\mathrm{m}$ & As above but for the maximum value. \\
\hline Woodland & Wood & $\%$ & $\begin{array}{l}\text { Amount of the catchment covered by woodland calculated from the CEH land cover maps } 2000 \text {. } \\
\text { This is an aggregation of broad-leaved/mixed woodland and coniferous woodland. }\end{array}$ \\
\hline Arable land & Arable & $\%$ & As above but using an aggregation of arable cereals, arable horticulture and arable non-rotational. \\
\hline Grassland & Grass & $\%$ & $\begin{array}{l}\text { As above but using an aggregation of improved grassland, neutral grassland, set-aside grassland, } \\
\text { bracken, calcareous grassland, acid grassland and fen, marsh and swamp. }\end{array}$ \\
\hline Mountain, heathland and bog & MHB & $\%$ & $\begin{array}{l}\text { As above but an aggregation of dense dwarf shrub heath, open dwarf shrub heath, bog (deep peat), } \\
\text { montane habitats and inland bare ground. }\end{array}$ \\
\hline Urban extent & Urban & $\%$ & As above but using an aggregation of suburban, urban and inland bare ground. \\
\hline Area & Area & $\mathrm{km}^{2}$ & Catchment area calculated using the IHDTM ${ }^{\mathrm{b}}$. \\
\hline Drainage path slope $\left(\mathrm{FEH}^{\mathrm{c}}\right)$ & Slope & $\mathrm{m} \mathrm{km}^{-1}$ & Mean drainage path slope calculated from the mean of all inter-nodal slopes (derived using IHDTM ${ }^{\mathrm{b}}$ ). \\
\hline $\operatorname{PROPWET}_{\left(\mathrm{FEH}^{\mathrm{c}}\right)}$ & PROPWET & $\%$ & Proportion of time soils are wet (defined as a soil moisture deficit of less than $6 \mathrm{~mm}$ ). \\
\hline $\mathrm{FARL}_{\left(\mathrm{FEH}^{\mathrm{c}}\right)}$ & FARL & Ratio & Flood attenuation attributed to reservoirs and lakes. \\
\hline Base flow index & BFI & Ratio & Calculated from mean daily flow using the method outlined in Gustard et al. (1992). \\
\hline No gleyed soils & S-no & $\%$ & Percentage of the catchment made up of HOST $^{\mathrm{d}}$ classes with no gleying: 1-8, 16 and 17. \\
\hline Deep gleyed soils & S-deep & $\%$ & Percentage of the catchment made up of HOST ${ }^{\mathrm{d}}$ classes with gleying between 40 and $100 \mathrm{~cm}: 13$ and $18-23$. \\
\hline Shallow gleyed soils & S-shallow & $\%$ & Percentage of the catchment made up of HOST ${ }^{\mathrm{d}}$ classes with gleying within $40 \mathrm{~cm}: 9,10,14,24$ and 25 . \\
\hline Peat soils & Peat & $\%$ & Percentage of the catchment made up of $\mathrm{HOST}^{\mathrm{d}}$ classes: $11,12,15,36$ and 29. \\
\hline Fracture high & F-high & $\%$ & Percentage of the catchment underlain by highly productive fractured rocks. \\
\hline Fracture medium & F-med & $\%$ & Percentage of the catchment underlain by moderately productive fractured rocks. \\
\hline Fracture low & F-low & $\%$ & Percentage of the catchment underlain by low productivity fractured rocks. \\
\hline Intergranular high & I-high & $\%$ & Percentage of the catchment underlain by highly productive intergranular rocks. \\
\hline Intergranular medium & I-med & $\%$ & Percentage of the catchment underlain by moderately productive intergranular rocks. \\
\hline Intergranular low & I-low & $\%$ & Percentage of the catchment underlain by low productivity intergranular rocks. \\
\hline No groundwater & no-GW & $\%$ & Percentage of the catchment underlain by rocks classed as having essentially no groundwater. \\
\hline
\end{tabular}

a Datum refers to Ordnance Datum, or in Northern Ireland, Malin Head Datum. ${ }^{b}$ IHDTM refers to the Integrated Hydrological Digital Terrain Model (Morris and Flavin, 1990). ${ }^{\mathrm{c}}$ FEH refers to catchment properties described in the Flood Estimation Handbook (Bayliss, 1999). ${ }^{\mathrm{d}}$ HOST refers to the hydrology of soil types classification (Boorman et al., 1995).

patterns for the SPI and SSI maximum duration and severity characteristics were similar for all three thresholds, and as such, only results for the -2 threshold (extreme drought) are shown. Results for the -1 and -1.5 thresholds can be found in the Supplement (Sect. S2; Figs. S1-S4).

For SPI-1, SPI-6 and SPI-18, there is little variation between the four clusters of catchments for the number of events and the median drought duration/severity characteristics (Fig. 2). This indicates that meteorological drought characteristics vary only modestly across the country over shorter accumulation periods once the precipitation has been standardised. The maximum duration/severity characteristics showed more differences between clusters, often showing a gradual change from clusters one to four. For SPI-1 the maximum duration of droughts in cluster one was generally short (between 4 and 9 months), whilst those in cluster four were longer (between 4 and 11 months). Similarly, for SPI-1 maximum severity, droughts in cluster one were less severe than those in cluster four. In contrast, the maximum duration and severity for SPI-6 was similar across all clusters, whilst for SPI-18 the median of the maximum duration decreases when moving from clusters one to three; the median of cluster four is higher than that of cluster two. The median maximum severity shows a different pattern for SPI-18 than for the shorter accumulation periods - median values increase (i.e. become less severe) moving from cluster one to three; cluster four has a lower (more severe) median severity than cluster three. Over these longer accumulation periods, inter-annual variability starts to become more influential; however, as will be discussed below (Sect. 5.1), the findings are somewhat surprising given that cluster one (mostly north-west Britain, 
Table 2. Median drought characteristics calculated for selected SPI and SSI accumulation periods using thresholds of $-1,-1.5$ and -2 for all catchments.

\begin{tabular}{|c|c|c|c|c|c|c|c|c|c|}
\hline \multicolumn{2}{|c|}{ Threshold } & \multirow[t]{2}{*}{$\begin{array}{l}\text { SPI/SSI accumulation } \\
\text { period (months) }\end{array}$} & \multirow[t]{2}{*}{$\begin{array}{r}\text { Total number } \\
\text { of events }\end{array}$} & \multicolumn{3}{|c|}{$\begin{array}{l}\text { Duration } \\
\text { (months) }\end{array}$} & \multicolumn{3}{|c|}{$\begin{array}{l}\text { Severity } \\
(-)\end{array}$} \\
\hline & & & & Mean & Median & Max. & Mean & Median & Max. \\
\hline \multirow{9}{*}{ SPI } & \multirow{3}{*}{-1} & 1 & 68 & 2.56 & 2 & 8 & -2.68 & -2.29 & -8.33 \\
\hline & & 6 & 20 & 9.72 & 8 & 24 & -9.69 & -6.91 & -30.88 \\
\hline & & 18 & 7 & 26.86 & 23 & 53 & -26.86 & -21.47 & -56.77 \\
\hline & \multirow{3}{*}{-1.5} & 1 & 36 & 2.75 & 2 & 7 & -3.29 & -2.83 & -8.33 \\
\hline & & 6 & 12 & 11.54 & 10 & 24 & -12.61 & -10.44 & -30.88 \\
\hline & & 18 & 5 & 30.20 & 27 & 53 & -33.34 & -29.11 & -56.77 \\
\hline & \multirow{3}{*}{-2} & 1 & 14 & 2.88 & 2.5 & 7 & -3.89 & -3.53 & -7.39 \\
\hline & & 6 & 6 & 13.20 & 12 & 24 & -16.45 & -14.33 & -30.88 \\
\hline & & 18 & 3 & 32.25 & 31 & 47 & -40.81 & -36.76 & -56.15 \\
\hline \multirow{9}{*}{ SSI } & \multirow{3}{*}{-1} & 1 & 42 & 3.81 & 3 & 13 & -3.95 & -3.10 & -16.84 \\
\hline & & 6 & 15 & 12.06 & 10 & 27 & -11.86 & -8.96 & -35.82 \\
\hline & & 18 & 6 & 31.00 & 27 & 53 & -31.35 & -25.74 & -57.79 \\
\hline & \multirow{3}{*}{-1.5} & 1 & 22 & 4.69 & 4 & 13 & -5.39 & -4.22 & -16.84 \\
\hline & & 6 & 9 & 14.80 & 14 & 28 & -16.60 & -14.29 & -35.93 \\
\hline & & 18 & 4 & 33.00 & 29.5 & 53 & -36.20 & -32.03 & -58.32 \\
\hline & \multirow{3}{*}{-2} & 1 & 7 & 5.75 & 5 & 12 & -7.64 & -5.93 & -16.84 \\
\hline & & 6 & 4 & 18.00 & 17 & 27 & -23.32 & -22.38 & -35.58 \\
\hline & & 18 & 2 & 34.83 & 34 & 45 & -44.88 & -44.00 & -53.78 \\
\hline
\end{tabular}

the wettest and most upland part of the country) displays the longest drought durations and most severe events.

Maps of meteorological drought characteristics based on SPI-1 and SPI-6 (Fig. 3) again show little spatial variability in either the number of events or event duration and severity. The number of events at the 18-month accumulation period also shows little spatial variability; however, the duration and severity maps show longer, more severe meteorological drought events occurring in northern England and Scotland.

For SSI (Fig. 4), there is a larger difference between the clusters for SSI-1 and SSI-6 than is seen in SPI for the same accumulation periods (Fig. 2). As was the situation for SPI-1, the differences between clusters occurs gradually from cluster one to four. For SSI-1 fewer, but longer and more severe, events are identified in cluster four than cluster one. As the SSI accumulation period increases to 18 months, there is less difference between the clusters (Fig. 4); much like the spatial trends seen for SPI-18 (Fig. 2), whereby cluster one has a much greater range in maximum duration and severity than the other three clusters.

Maps of hydrological drought characteristics based on SSI show more spatial variability (Fig. 5) than the meteorological drought characteristics (Fig. 3). For SSI-1 and SSI-6, fewer, longer, more severe events occur in the south and east. As the accumulation period lengthens to 18 months, longer, more severe events occur in Scotland and the north of England. Despite this, the number of events remains fewer than 10 throughout the UK, with the most events occurring in the south-east of England.

Time series plots of SPI for selected accumulation periods in Fig. 6 and SSI in Fig. 7 show the highly variable time series for the 1-month accumulation period. As the accumulation period increases to 6 and 18 months, the time series become smoothed, with both wet and dry periods becoming more prolonged. Figure 6 also shows that at the longer accumulation period (SPI-18) for the two Scottish case study catchments (the Dee and Cree), the early time series is dominated by dry events, while the later time series is dominated by wet events. This is in contrast to the remaining case study sites in England and Wales, which show more regular fluctuations between wet and dry events throughout the SPI time series. Similar long-term trends can be seen in the SSI time series for the case study catchments in Fig. 7. The implications of these patterns for application of the SPI and SSI will be returned to in the discussion (Sect. 5.1).

\subsection{Drought propagation}

Pearson correlations between SSI-1 and different accumulation periods of SPI (1-24 months) showed that for the majority of catchments, SPI- $n$ (i.e. the SPI accumulation period with the strongest correlation with SSI-1) was 1, 2 and 3 months (50, 38 and 10 catchments, respectively; Fig. 8). The longest SPI- $n$ was 19 months (correlation, $r$, associated 


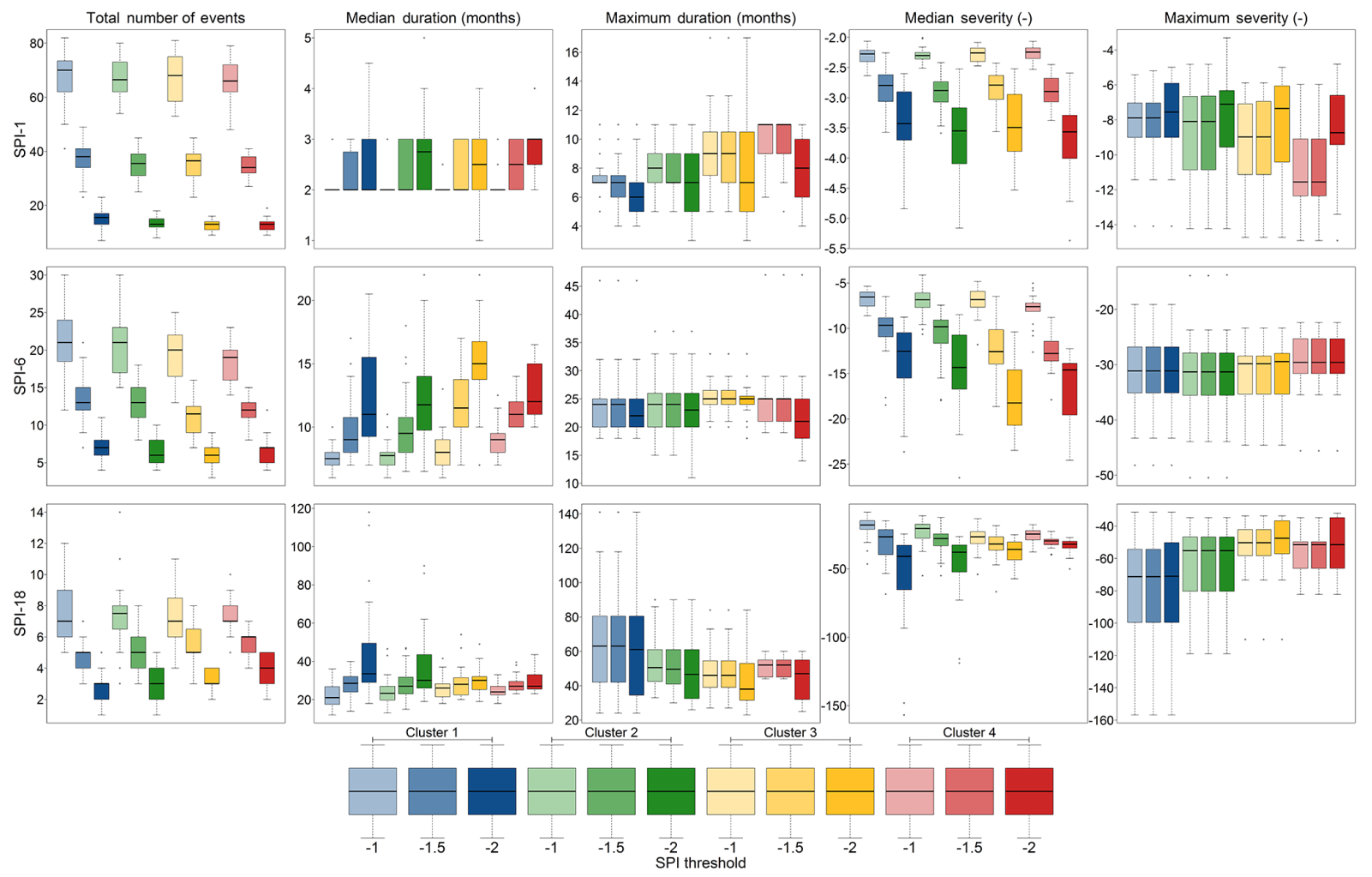

Figure 2. Boxplots showing meteorological drought characteristics based on SPI using thresholds of $-1,-1.5$ and -2 for each cluster. Note that the $y$ axis scale is different for each accumulation period to best show the full variability of the results.

with SPI- $n=0.85$ ) followed by 16 months ( $r$ value associated with SPI- $n=0.83$ ), both located in south-east England.

Figure 8 shows that for catchments in the north and west of the UK, SPI- $n$ was between 1 and 4 months, whilst in the south and east SPI- $n$ was longer (between 1 and 19 months). The most northerly catchment where SPI- $n$ is longer than 4 months was on the east coast, where SSI-1 was most strongly correlated with SPI-12 $(r=0.80)$. The locations of catchments with longer SPI- $n$ in the south and east mostly coincide with the location of major UK aquifers (Fig. 8); the relationship between this indicator of drought propagation and physical catchment properties will be explored further in Sect. 4.3.

Figure 9 shows the correlations between all SPI accumulation periods (1-24 months) and SSI-1. The strength of the correlations reflects the spatial variability seen in SPI- $n$ (Fig. 8). Catchments in the north and west show the strongest correlations at accumulation periods of 6 months or less, the majority of which (particularly in western Britain) show the maximum correlation at SPI-1, compared with those in the south and east where strong correlations are found at the full range of SPI accumulation periods (1-24 months). Some catchments do not fit this geographical generalisation. For example, some catchments in Scotland and Wales show strong correlations between SPI and SSI-1 across a range of SPI accumulation periods, whilst several catchments in south-east England show the strongest correlation at short SPI accumulation periods and weaker correlations at longer SPI accumulation periods.

When SPI values (for accumulation periods of 124 months) were correlated with lagged SSI-1, the strongest correlation was found at a lag of zero months (i.e. no lag) for all catchments. One would expect the SPI accumulation period most strongly correlated with lagged SSI-1 (lagged SPI- $n$ ) to be a function of the autocorrelation in the SSI-1 time series. To examine this, the longest $\mathrm{n}$-month period for which there is significant autocorrelation in SSI- $1(\alpha=0.05$; autocorrelation max) is also shown in Fig. 10 on the $y$ axis for the SSI-1 with zero lag. For the nine case study catchments, the autocorrelation max is very close to (in all cases within 4 months) the lagged SPI- $n$. The autocorrelation max for the Cree occurs at zero months (and so is not shown in Fig. 10), showing there is no month-to-month autocorrelation in the flows. When looking at all catchments (as in Fig. 9), the lagged SPI- $n$ and the autocorrelation max was the same or 1 month different for over $80 \%$ of catchments.

Case study catchments in the south and east (Harpers Brook, Thet, Lambourn and Great Stour) show stronger and significant $(\alpha=0.05)$ correlations across a range of both SPI accumulation periods and lags than those in the north and 


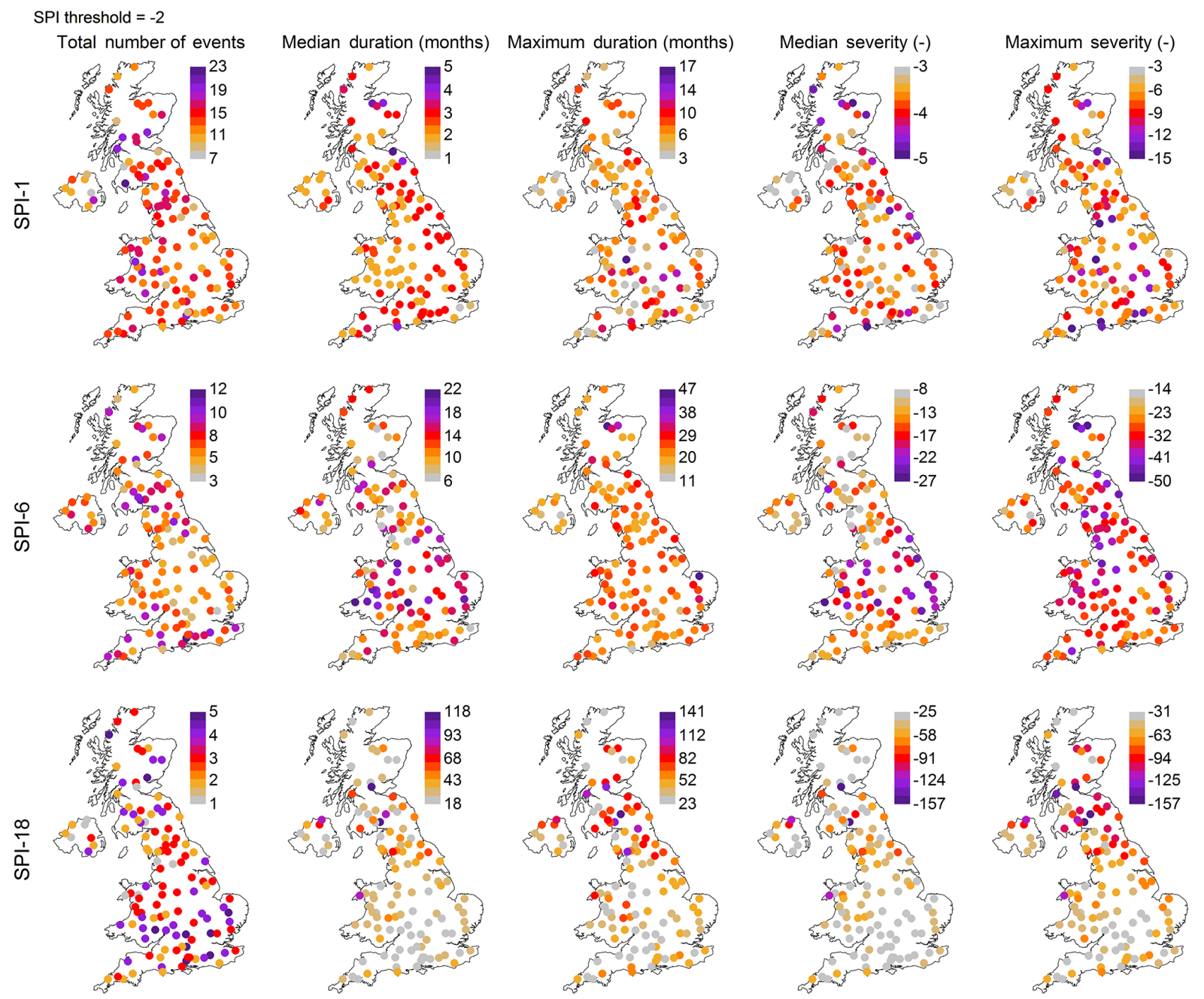

Figure 3. Maps showing selected meteorological drought characteristics based on SPI-1, SPI-6 and SPI-18 using a threshold of -2 . Note that the colour scale is different for each accumulation period to best show the spatial variability of the results.

east (Dee, Cree, South Tyne, Teifi and Torridge; Fig. 10). These northern and western catchments show strong, significant correlations at shorter SPI accumulation periods and lags, and as lag increases, the strength and significance of correlations decrease. Case study catchments in the north and west (south and east) can be characterised by generally low (high) BFI values. For all catchments, there was a strong correlation between the lagged SPI- $n$ and BFI $(r=0.79$, $\alpha=0.001)$. Although BFI showed a strong correlation with the lagged SPI- $n$, because of the climatic, geological and land-surface heterogeneity in the UK, other climate and catchment properties are also likely to be influential; these are discussed in the following section (Sect. 4.3).

\subsection{Links with climate and catchment properties}

\subsubsection{Relative importance of rainfall and catchment storage on hydrological droughts across clusters}

Table 3 shows the Spearman correlations between hydrological drought characteristics (based on SSI and includes a propagation indicator, SPI- $n$ ) and SAAR for clusters one and two, clusters three and four and all catchments grouped together. The Spearman correlations for all catchments showed stronger, highly significant correlations $(\alpha=0.001)$ between SAAR and the hydrological drought characteristics. Correlations for clusters one and two are stronger, and significant $(\alpha=0.01)$, than those for clusters three and four, which were weak and non-significant. This suggests that the general precipitation climate is more influential in determining hydrological drought characteristics and propagation in clusters one and two than it is in clusters three and four, where the 


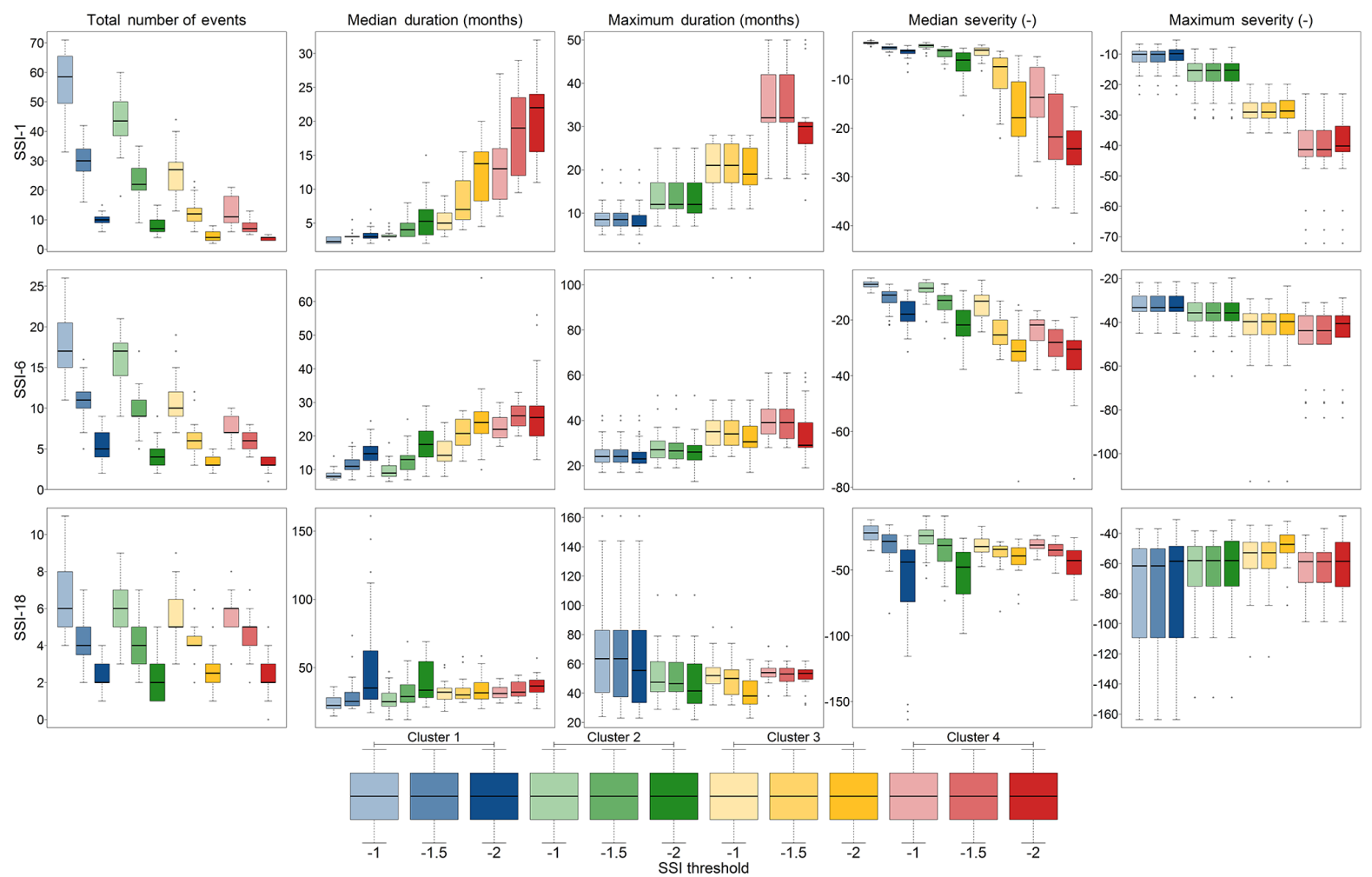

Figure 4. Boxplots showing hydrological drought characteristics based on SSI using thresholds of $-1,-1.5$ and -2 for each cluster. Note that the $y$ axis scale is different for each accumulation period to best show the full variability of the results.

within-cluster precipitation climate is uniform and the geology is more heterogeneous. However, the significance of these correlations is likely to be a result of (a) the strong precipitation gradient between the north-west and the south-east of the UK, and (b) the unequal number of catchments in each group - there are 71 catchments in clusters one and two and 50 catchments in clusters three and four.

Figure 11 shows the relationship between SAAR and hydrological drought characteristics for all catchments, with points coloured by BFI to give an indication of the relationship between the hydrological drought characteristics and catchment storage. The plots show BFI decreasing as SAAR increases, a reflection of the fact that most high BFI, i.e. high storage, catchments are located in lowland south-east England that receives less precipitation. Figure 11 shows positive relationships between SAAR and median/maximum severity, but as SAAR reaches $\sim 1000 \mathrm{~mm}$, there is little change in the hydrological drought and propagation characteristics for further increases in SAAR. There was a negative correlation between SAAR and median/maximum duration and SPI- $n$, but again, there was little change in the hydrological drought and propagation characteristics for SAAR values over $1000 \mathrm{~mm}$. The strong, significant $(\alpha=0.001)$ relationships for all catchments between SAAR and the hydrological drought characteristics are shown in Table 3.
Figure 12 shows the relationship between SAAR, hydrological drought characteristics and propagation but for catchments in clusters three and four only (the results for clusters one and two are not shown as they are broadly similar to the results for the full data set). The relationship with SAAR for these clusters, as shown in Table 3, is weaker than those for all catchments (Table 3, Fig. 11). Instead, it is clear that catchments from clusters three and four can be split into two groups, those with higher BFI values and those with lower BFI values (Fig. 12); catchments were split based on the median BFI for clusters three and four. Each group separately follows the same relationship with SAAR, as described for the full data set in Table 3 and Fig. 11. This is with the exception of the $r$ value associated with SPI- $n$ and SAAR, which shows opposite relationships - positive (negative) for low (high) BFI catchments. These results show that SAAR is strongly correlated with hydrological drought and propagation characteristics for catchments in clusters one and two. For catchments in clusters three and four, catchment storage, as indexed by BFI, is more influential in determining hydrological drought characteristics and propagation than precipitation. The following section considers whether catchment properties, including those that describe and influence storage, can explain hydrological drought and propagation characteristics. 

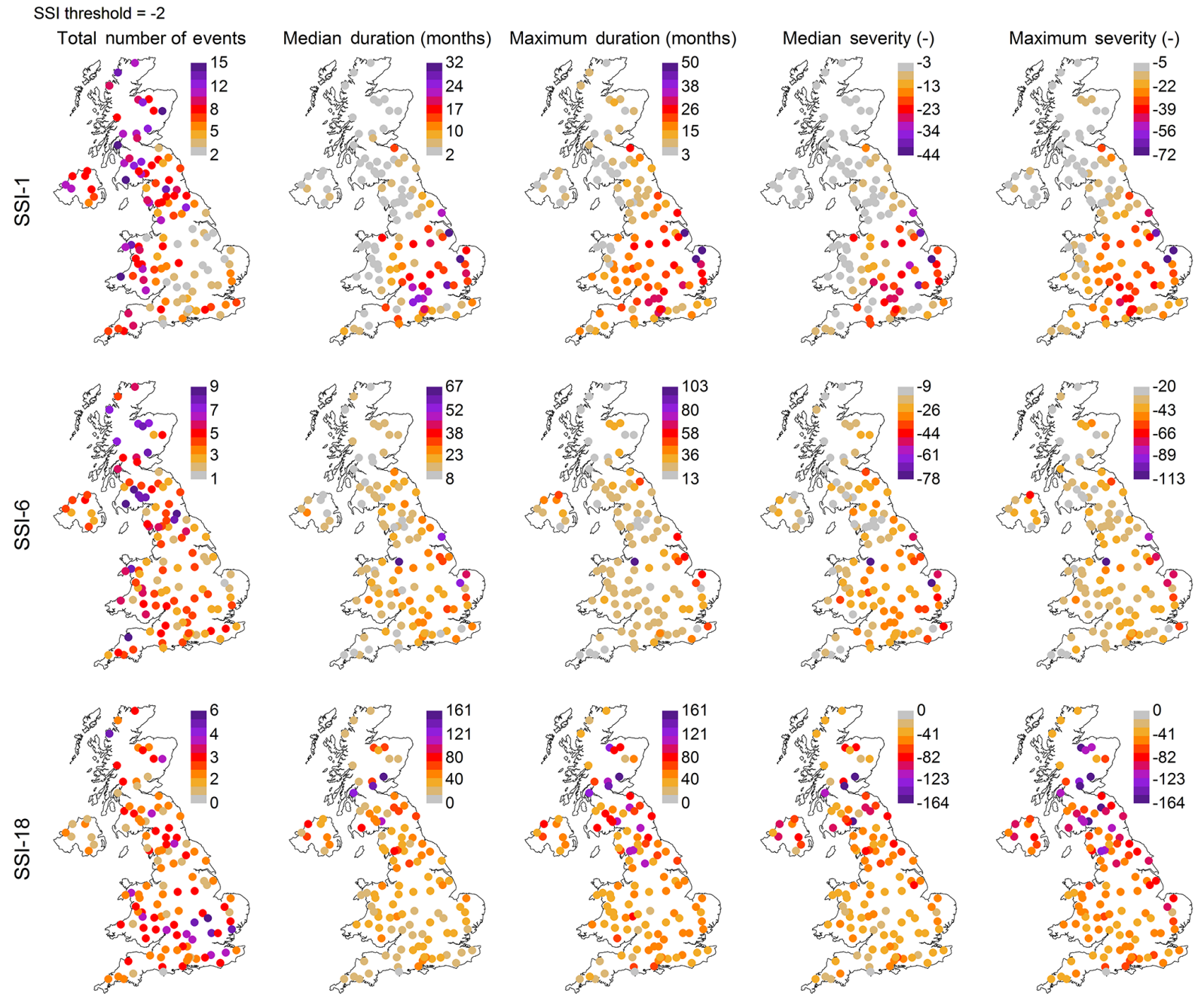

Figure 5. Maps showing selected hydrological drought characteristics based on SSI-1, SSI-6 and SSI-18 using a threshold of -2 . Note that the colour scale is different for each accumulation period to best show the spatial variability of the results.

Table 3. Correlation coefficients for Spearman correlations between hydrological drought characteristics and SAAR $\left({ }^{*} \alpha=0.1 ; * * \alpha=0.01\right.$; *** $\alpha<0.001)$. Drought characteristics were calculated using SSI-1 and a threshold of -1 .

\begin{tabular}{lrrr}
\hline Drought characteristic & Clusters one and two & Clusters three and four & All catchments \\
\hline Total number of events & $0.47^{* * *}$ & 0.12 & $0.76^{* * *}$ \\
Median duration (months) & $-0.52^{* * *}$ & -0.14 & $-0.77^{* * *}$ \\
Maximum duration (months) & $-0.57^{* * *}$ & -0.25 & $-0.78^{* * *}$ \\
Median severity (-) & $0.54^{* * *}$ & 0.08 & $0.76^{* * *}$ \\
Maximum severity (-) & $0.60^{* * *}$ & 0.14 & $0.81^{* * *}$ \\
SPI- $n$ (months) & $-0.51^{* * *}$ & 0.00 & $-0.76^{* * *}$ \\
SPI- $r$ value & $0.68^{* * *}$ & 0.26 & $0.69^{* * *}$ \\
\hline
\end{tabular}

\subsubsection{Influence of catchment properties on hydrological droughts}

Hydrological drought characteristics for clusters one and two showed strong correlations with elevation properties. This, in conjunction with the strong correlations between the hy- drological drought characteristics and SAAR (Table 3), indicate that the climatological control is the dominant factor influencing hydrological drought characteristics in the typically wet, upland catchments of clusters one and two mainly located in the north and west of the UK. The variation in 


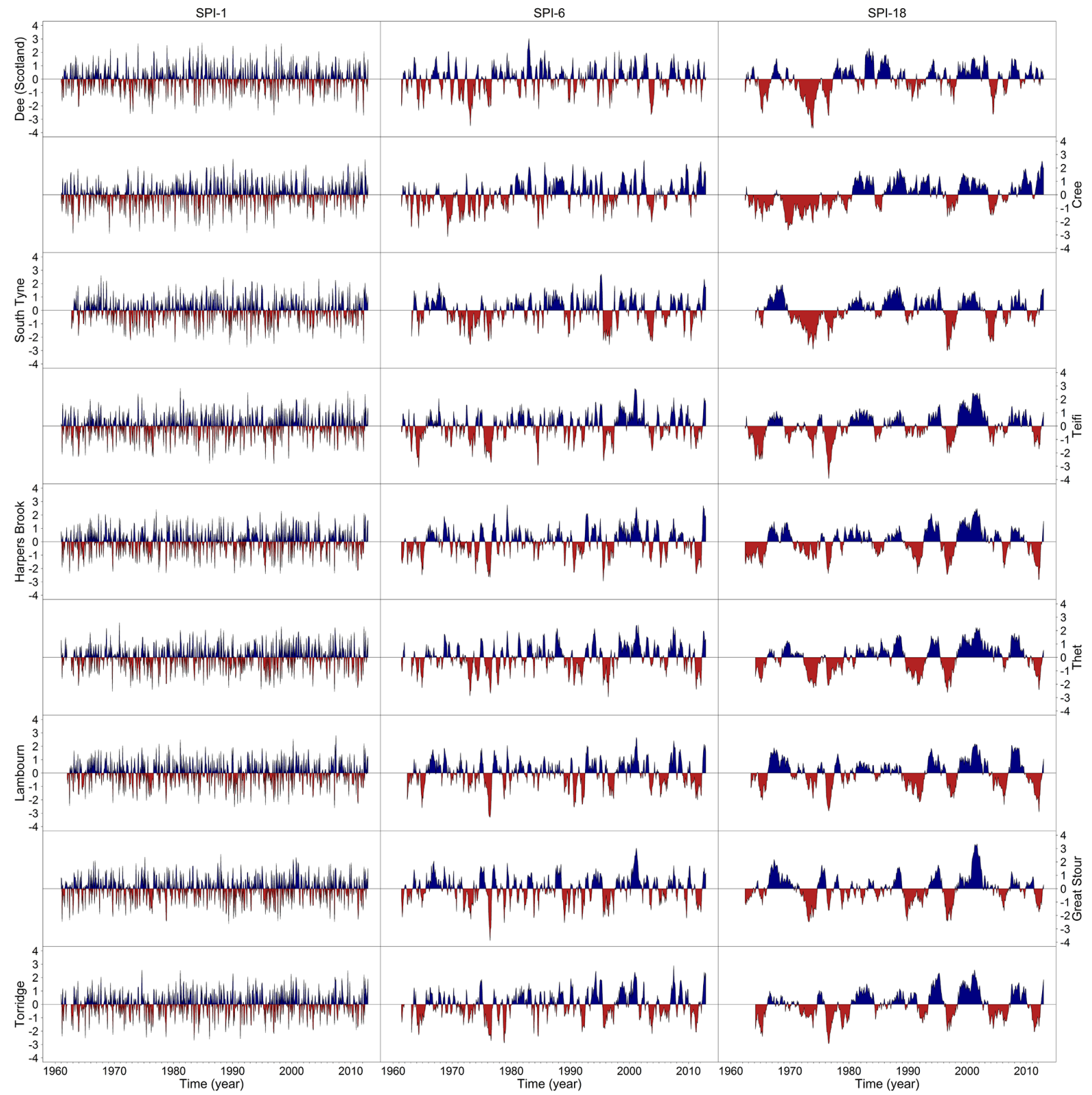

Figure 6. Case study catchment SPI time series for selected accumulation periods.

precipitation across the lowland south and east is relatively minor in comparison to the north and west of the UK, but exhibits heterogeneity in geology and land cover, allowing catchment properties to exert a greater control on the hydrological drought characteristics in clusters three and four. As such, in the following sections, only results for clusters three and four are presented and discussed. The correlations between hydrological drought characteristics and catchment properties for clusters one and two can be found in the Supplement (Sect. S3; Fig. S5).

Figure 13 shows that when clusters three and four are grouped together, both the median and maximum hydrolog- ical drought duration have a strong positive correlation with catchment properties related to storage, such as the percentage of highly productive fractured rock $(r=0.78$ and 0.59 , respectively) and BFI ( $r=0.73$ and 0.56 , respectively). Correlations of catchment properties with severity characteristics were generally of a similar strength, but where duration characteristics showed positive correlations, severity characteristics showed negative correlations (and vice versa). The number of events was most strongly correlated with the percentage of highly productive fractured rock $(r=-0.70)$ and BFI $(r=-0.68)$, both of which were significant $(\alpha=0.001)$. These two catchment properties were also most strongly cor- 


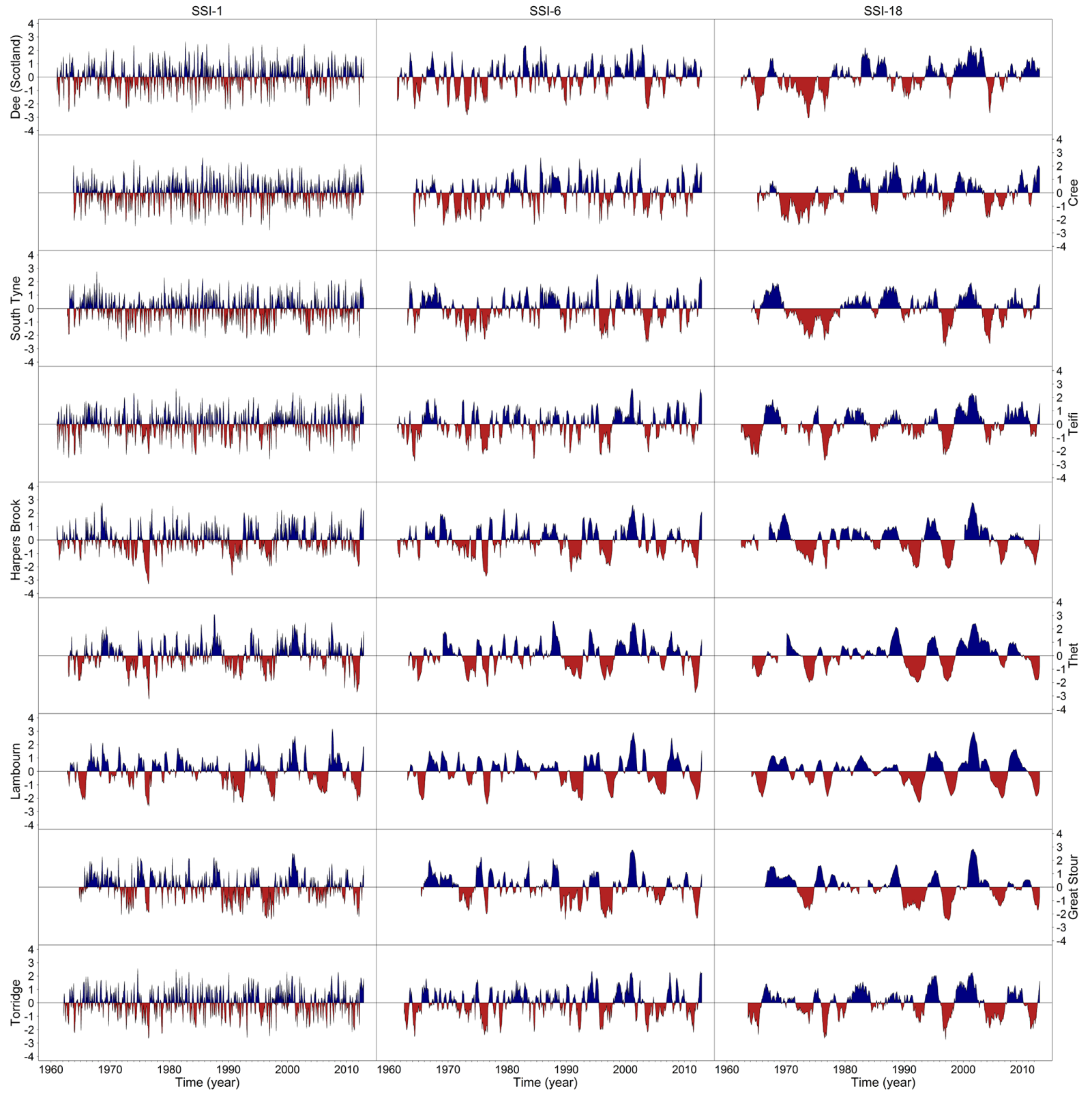

Figure 7. Case study catchment SSI time series for selected accumulation periods.

related with SPI- $n$ ( $r=0.81$ and 0.83 , respectively). The percentage of highly productive intergranular rocks showed significant relationships with all hydrological drought characteristics $(\alpha=0.001)$, whilst the percentage of moderately productive intergranular rocks showed weaker and less significant relationships $(\alpha=0.1,0.01$ or 0.001$)$. The percentage of low productivity intergranular rocks on the other hand showed negative correlations where the percentage of highly and moderately productive intergranular rocks showed positive correlations, and both duration characteristics and SPI- $n$ correlations were significant $(\alpha=0.1)$.
PROPWET has significant correlations with all the hydrological drought characteristics (except the $r$ value associated with SPI- $n$ ). Positive relationships were found between PROPWET and the number of events, severity characteristics and the $r$ value associated with SPI- $n$. The remaining hydrological drought characteristics had negative correlations with PROPWET. The percentage of shallow gleyed soils was third most strongly correlated with the number of events, median duration and median severity. It showed similar correlations to those of PROPWET, but correlations were generally stronger and more significant. The percentage of peat soils showed similar, if weaker and less significant, correlations 


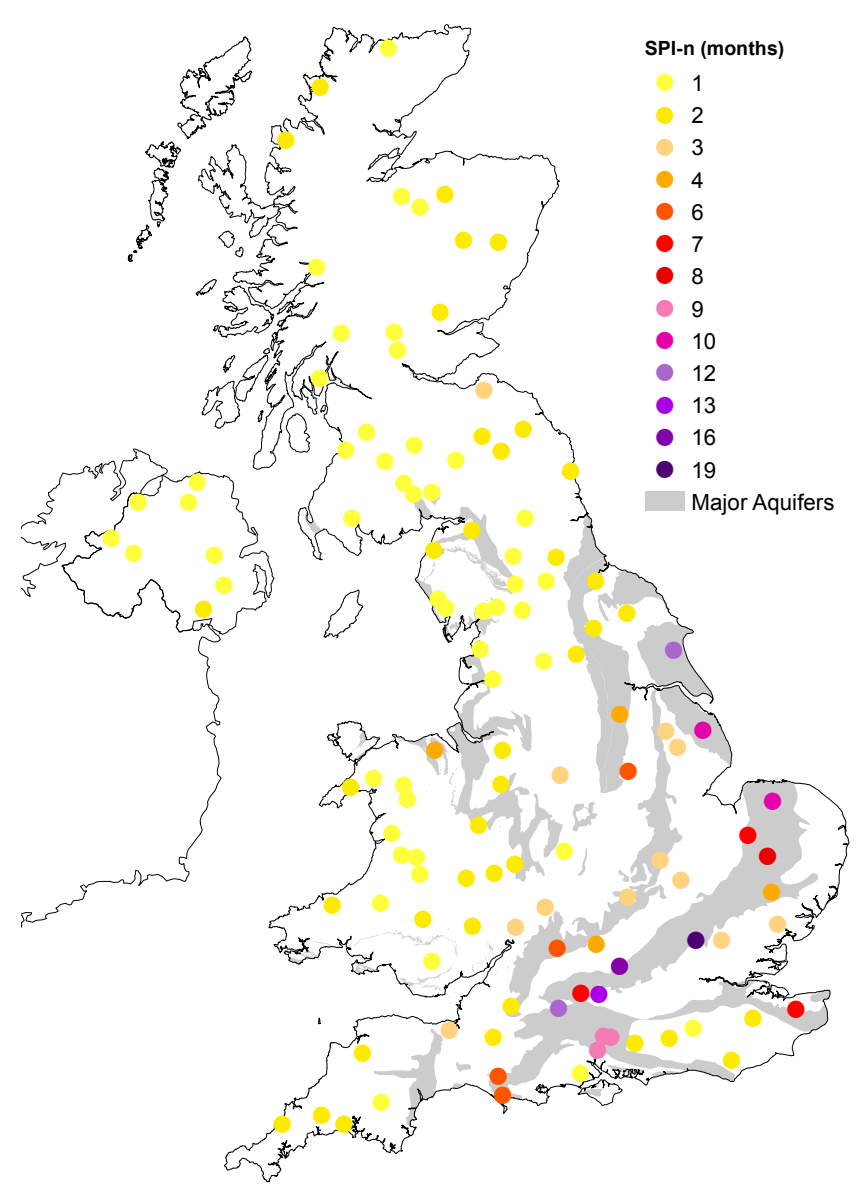

Figure 8. Map of catchments showing the SPI accumulation period most strongly correlated with SSI-1 (SPI- $n$ ) and the location of major UK aquifers.

with the percentage of shallow gleyed soils and PROPWET. The percentage of no gleyed soil showed correlations of a similar strength and significance with the percentage of shallow gleyed soils but of the opposite sign (i.e. where the percentage of shallow gleyed soils correlations was positive, the percentage of no gleyed soils was negative, and vice versa). In contrast, the percentage of deep gleyed soils showed very weak or no correlation with the hydrological drought characteristics.

The percentages of arable land and grassland were significantly correlated for all hydrological drought characteristics $(\alpha=0.1,0.01$ or 0.001$)$, with the exception of the $r$ value associated with SPI- $n$. The percentage of grassland showed correlations of the opposite sign: where the percentage of arable land had a positive correlation with hydrological drought characteristics, the percentage of grassland had a negative correlation. The percentage of woodland showed significant correlations, of the same sign as the percentage of grassland, between the number of events, median dura- tion, median severity, maximum severity $(\alpha=0.1)$ and SPI- $n$ $(\alpha=0.01)$.

All hydrological drought and propagation characteristics were weakly correlated with catchment properties such as area, slope, the percentage of mountain, heathland and bog and elevation properties (generally non-significant). The use of "near-natural" Benchmark catchments meant that they are little influenced by urban areas or regulation; as such, the catchment properties urban extent and FARL were excluded from the analysis.

\section{Discussion}

\subsection{Drought characteristics}

Drought characteristics were extracted from SPI and SSI time series from a wide and representative sample of UK catchments. This provides a comprehensive view of meteorological and hydrological droughts at the national scale, assessed using the standardised indicators that have been relatively under-used in the UK. Overall, the results show that, for shorter accumulation periods, there is comparatively little difference between catchment types (as shown by the clusters, Fig. 2) or around the country in meteorological drought characteristics extracted from SPI time series (Fig. 3). Although the UK has an order of magnitude precipitation gradient across the country, there is little difference in the median of the meteorological drought characteristics. Similarly, Van Loon and Laaha (2015) found little spatial variation in the number and average duration of meteorological events between clusters of Austrian catchments. However, this study shows that there are pronounced regional differences in the maximum drought duration and severity, which is supported by Folland et al. (2015), who note that the north-west has a more variable climate and the south-east is subject to longer dry spells, and that in practice the two regions experience droughts in opposition. Regional differences in meteorological drought duration and severity have also been found elsewhere, e.g. in Valencia, where spatial variation was found to be the result of both catchment relief and climatic variability across the region (Vicente-Serrano et al., 2004).

In contrast, hydrological drought characteristics extracted from SSI time series show distinct regional variations and differences between catchment types. SSI-1 and SSI-6 results show fewer, longer, more severe droughts occurring in southern and eastern regions of England, which are dominated by groundwater-fed rivers on permeable aquifer outcrops (Figs. 4 and 5). These results parallel those seen in Vidal et al. (2010), who found fewer, but longer, and more severe events in gridded, modelled streamflow data in northern France, which is dominated by groundwater-fed rivers and large aquifer systems, than in southern France. These results show that although standardisation is carried out for each month, the month-to-month autocorrelation in stream- 


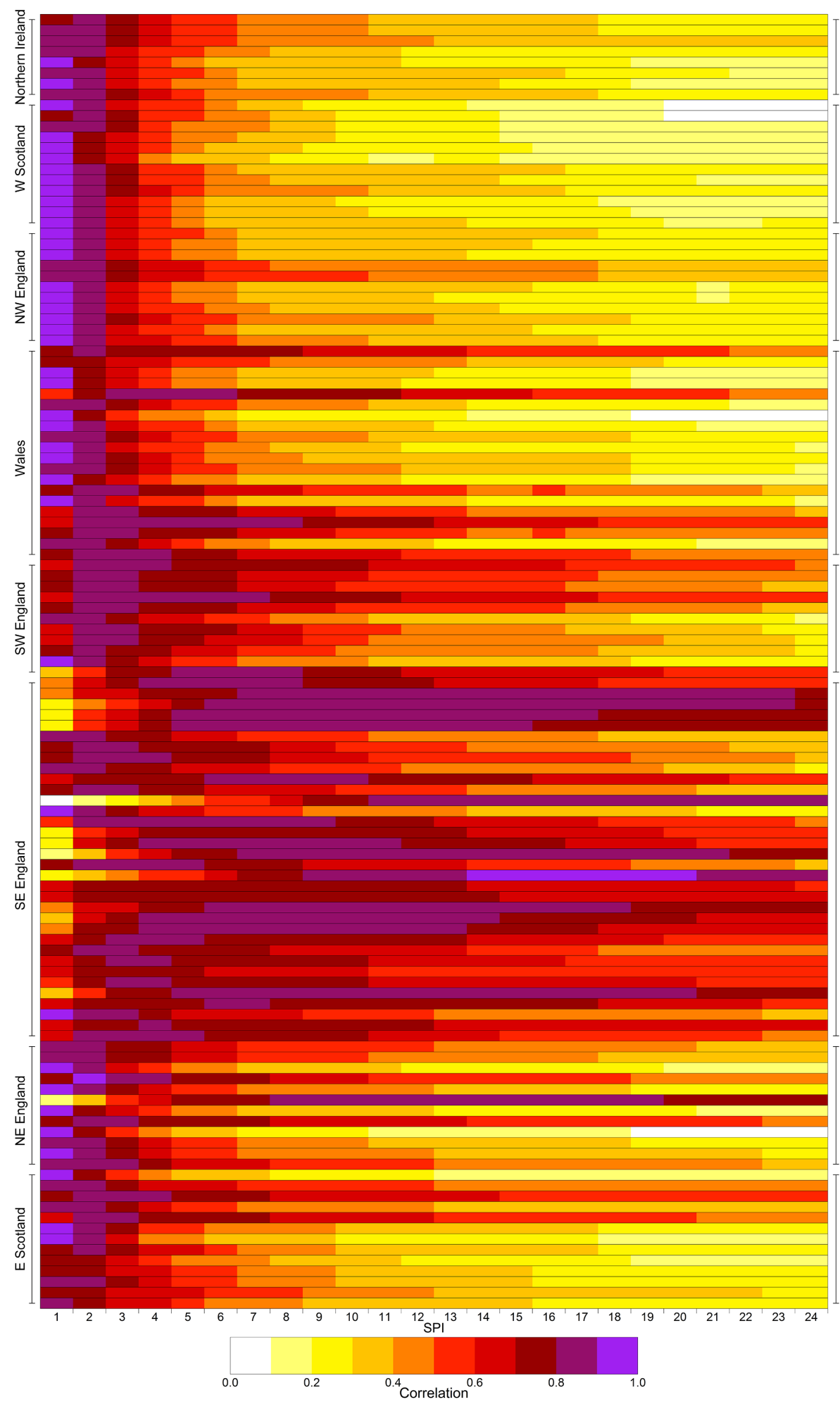

Figure 9. Heat map showing correlations of SPI accumulation periods of 1-24 months with SSI-1 for all catchments.

flow means that droughts defined using a given SSI threshold can take on very different characteristics around the country, according to hydrological memory.
Given the climatological gradient in the UK, the long, severe droughts identified using SPI-18 and SSI-18 in Scotland were unexpected (Figs. 3 and 5). Previous studies charac- 


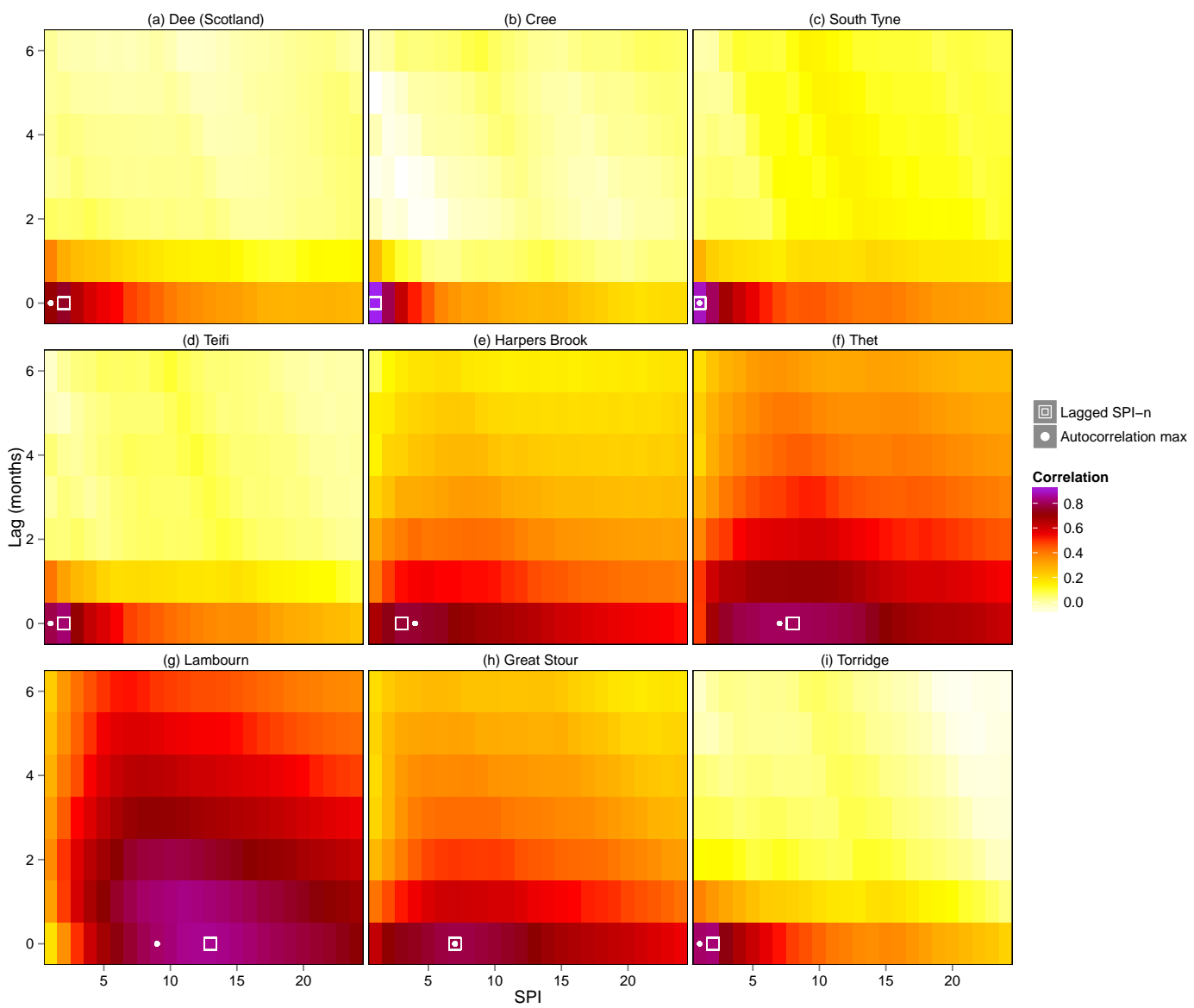

Figure 10. Heat maps for case study catchments showing correlation between SSI-1 lagged by 0-6 months and SPI accumulation periods of 1-24 months. The lagged SPI- $n$ is shown, as is the longest $n$-month period for which there is significant autocorrelation in SSI- 1 (autocorrelation max).

terise droughts in Scotland as being shorter and less severe than those in the south and east of England (Jones and Lister, 1998; Marsh et al., 2007). These apparent long droughts are a result of strong long-term increasing temporal trends in run-off, primarily driven by the inter-decadal variability in the North Atlantic Oscillation, as have been widely reported (e.g. Hannaford, 2015). As there is a strong trend, the standardised approach makes it appear that there is one long drought in the early record and pronounced wetness at the end (Figs. 6 and 7). In one sense, this is a perfectly valid finding; the dryness of the early period is important when examining long meteorological droughts. However, in another sense, it is misleading, as "droughts" (in terms of triggering a particular impact) with a duration of 18 months are less influential on reservoir levels and water resources planning in the north and west of the UK. This is, in part, due to the lack of sub-surface storage in these responsive catchments. A short and intermittent wet spell can return the catchment to normal conditions as there is limited storage in which to build up deficits. The dangers of using standardised indicators in the presence of non-stationarity and multi-decadal variability in atmosphere-ocean drivers have been highlighted elsewhere (e.g. McCabe et al., 2004; Núñez et al., 2014).

\subsection{Drought propagation}

SSI-1 was cross-correlated with SPI accumulation periods of 1-24 months to identify the timescale over which precipitation deficits propagate through the hydrological cycle to produce streamflow deficits. The mapping of SPI- $n$ (the SPI accumulation period most strongly correlated with SSI1) in Fig. 8 identified a strong spatial pattern reflecting the north-west to south-east precipitation and geological gradient found in the UK. Many of those catchments in the south and east where the SPI- $n$ is longer are located in regions underlain by major aquifers. In 14 boreholes in England and Wales, Bloomfield and Marchant (2013) found that the Standardised Groundwater Index (SGI) was most strongly correlated with SPI accumulation periods of 6-28 months. The SPI accumulation period most related to the SGI was site specific and related to hydrogeological properties of the aquifers. Similar results were found in southern Germany 

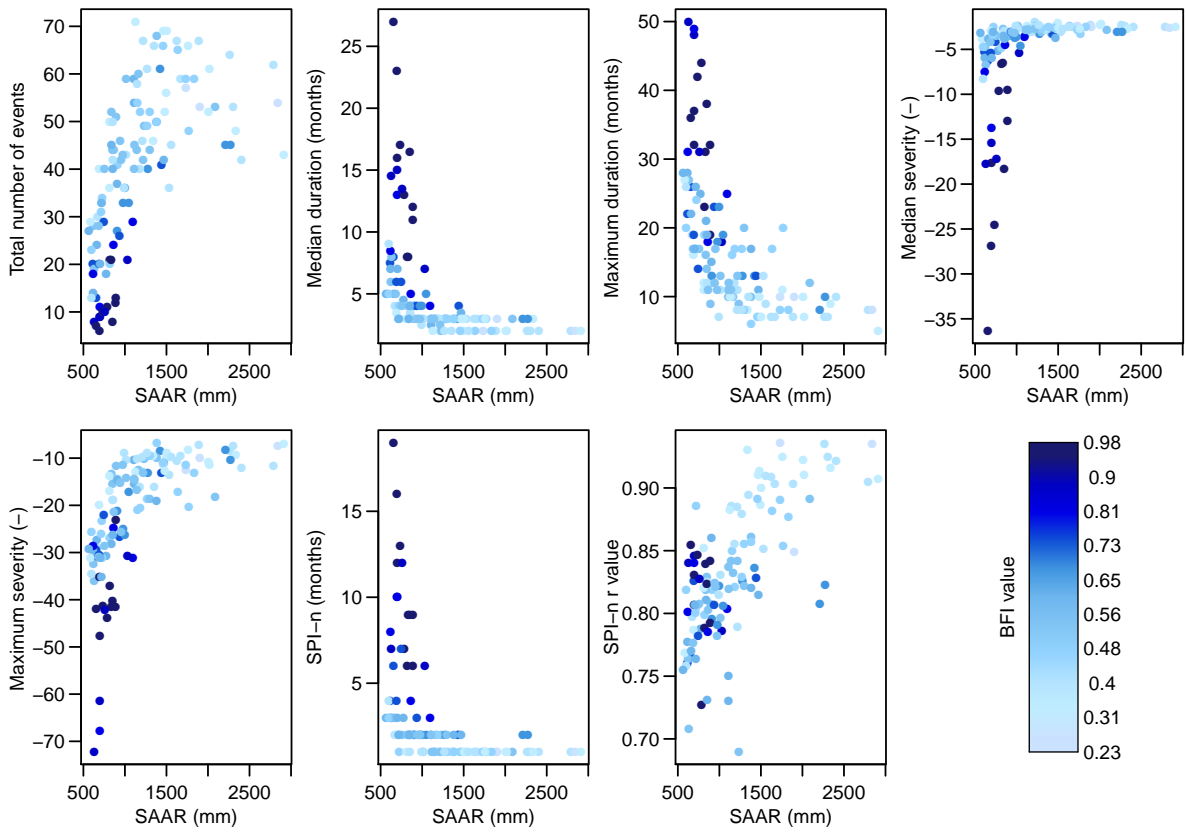

Figure 11. Relationship between hydrological drought characteristics based on SSI-1 using a threshold of - 1 and SAAR for all catchments.
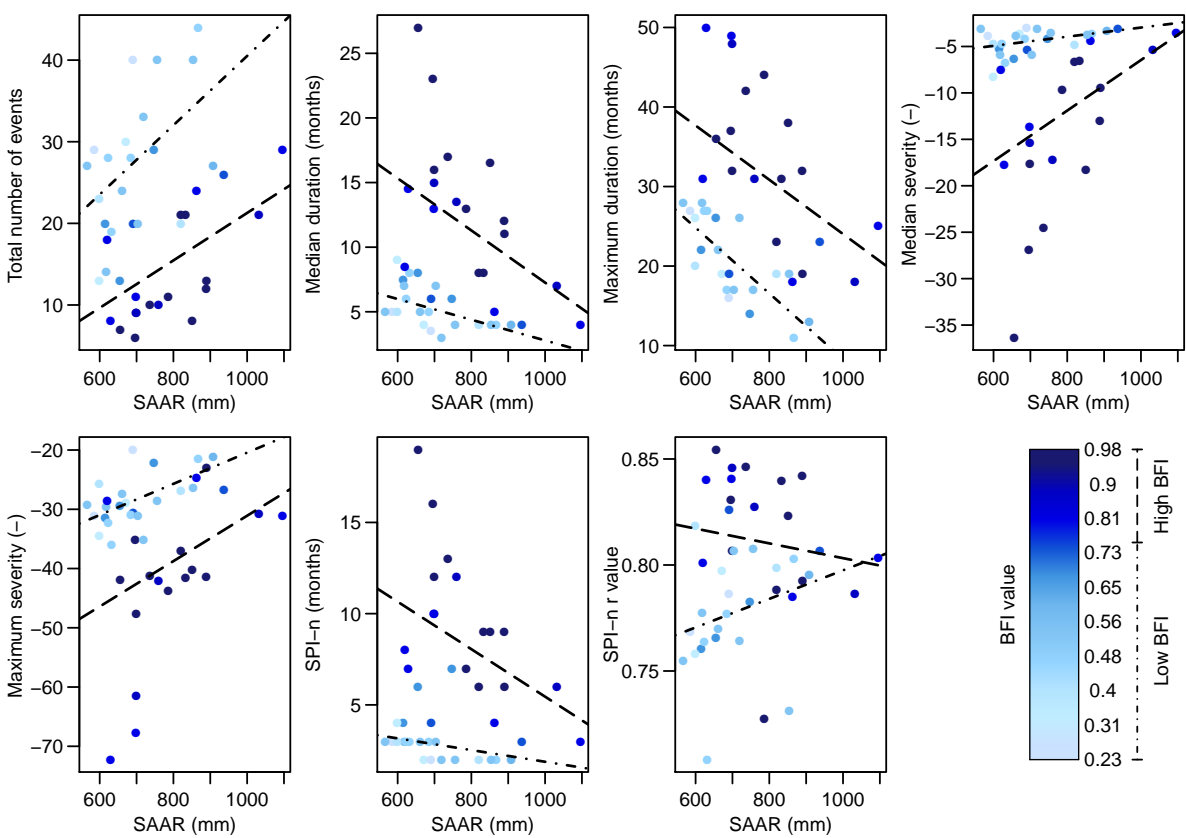

Figure 12. Relationship between hydrological drought characteristics based on SSI-1 using a threshold of -1 and SAAR for catchments in clusters three and four.

and the central Netherlands (Kumar et al., 2016). LorenzoLacruz et al. (2013b) found that SSI-1 was more strongly correlated with SPI-12 in southern Spain, where many catchments have limestone headwaters, contrasting with catchments on less permeable geologies that showed stronger correlations for short SPI accumulation periods. VicenteSerrano and López-Moreno (2005) also found that SPI was strongly correlated with standardised streamflow over accumulation periods of 1 to 3 months in a responsive catchment with little storage in the central Spanish Pyrenees.

Figure 9 shows the strong correlations of SSI-1 with a range of SPI accumulation periods. Although, in general, catchments in the south and east can be said to be permeable, there is a range of geologies and not all catchments are 


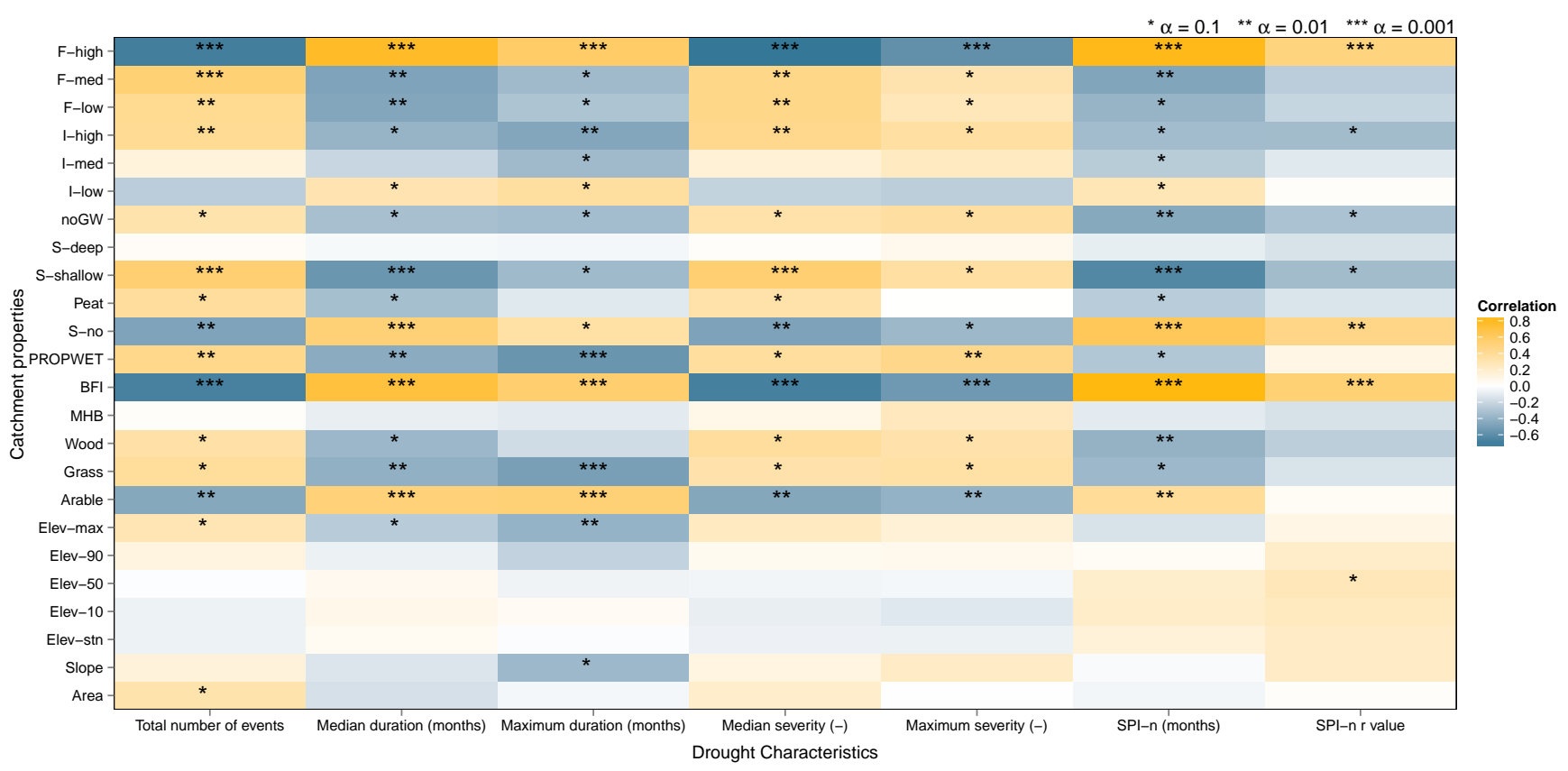

Figure 13. Heat map showing the correlations between selected hydrological drought characteristics based on SSI-1 using a threshold of -1 and catchment properties for catchments in clusters three and four. See Table 1 for descriptions of the catchment properties.

highly permeable or are largely influenced by groundwater. In less permeable catchments, the strong correlations at long SPI accumulation periods are likely to be partially a result of the stronger seasonality in the south and east where evapotranspiration is higher (Kay et al., 2013). Where this enhanced seasonality in effective rainfall (precipitation minus evapotranspiration) induces a stronger relationship between streamflow on successive days, autocorrelation in streamflow increases (Chiverton et al., 2015b). This autocorrelation favours the longer SPI accumulation periods.

The lagged correlations for the Lambourn, Thet and Great Stour all show strong correlations across both a range of lags and SPI accumulation periods (Fig. 10) just as lagged correlations of SPI do with the SGI (Bloomfield and Marchant, 2013). While we find (along with Folland et al., 2015) the strongest correlation with streamflow occurs when SPI is not lagged, the presence of strong correlations even at lags of several months (up to 6 months, in some cases) demonstrates potential for early warning of hydrological drought based on persistence of meteorological anomalies. Indeed, this characteristic is already used for making successful seasonal streamflow forecasts based on persistence in the UK (Svensson, 2016). This forecasting method currently estimates whether flows are likely to be in high, medium or low bins, but the results presented here suggest that further work could focus more specifically on drought indicators. Rivers in the north and west do not benefit from the slow release of stored groundwater; instead, methods that reflect the expected meteorological conditions are needed for making skilful streamflow forecasts (Svensson et al., 2015a). The closeness of the lagged SPI- $n$ and the largest lag for which there is significant autocorrelation in SSI-1 (autocorrelation max) suggests that lagged SPI- $n$ is dependent on the autocorrelation in monthly flows - indeed, lagged SPI- $n$ and the autocorrelation max are significantly correlated $(r=0.85$, $\alpha=0.001)$.

\subsection{Links with climate and catchment properties}

Analysis of SAAR and hydrological drought characteristics showed that for upland catchments (clusters one and two), the general precipitation climate (characterised by SAAR) was much more important in influencing hydrological drought characteristics (Table 3) than in lowland catchments (clusters three and four; Table 3, Fig. 12). Table 3 and Fig. 11 also show the strong relationship between SAAR and the hydrological drought characteristics for all catchments together, a result of the prominent precipitation gradient seen between the north-west and the south-east of the UK. Similarly, Haslinger et al. (2014) found that climate was more influential than catchment properties in Austrian catchments, where small-scale geological differences could not explain the variation in correlation significance between streamflow and meteorological drought indices across four geologically similar regions. Precipitation was found to be necessary to produce a significant model of median discharge drought duration, in addition to catchment properties for Austrian catchments (Van Loon and Laaha, 2015). A combination of the weather type (based on the objective Grosswetterlagan weather classification) and catchment properties was found 
to contribute to the hydrological response time in catchments across the UK and Denmark (Fleig et al., 2011). On a broader scale, in a study of 808 near-natural streamflow records in Europe and the USA, Tijdeman et al. (2015) found that climate classification systems that included absolute precipitation were best for differentiating catchments based on hydrological drought duration. In addition, BFI, the seasonality of precipitation and the occurrence of hot summers were important individual controls on hydrological drought duration.

For clusters three and four, mainly located in the lowland south and east of the UK, SAAR was weakly correlated with hydrological drought characteristics (Table 3, Fig. 12). A small range of, and generally lower, average annual precipitation, and the presence of permeable aquifer outcrops, means that catchment properties, particularly those related to catchment storage (for example, BFI, percentage of highly productive fractured rock and PROPWET), are more influential than SAAR in determining the drought and propagation characteristics (Fig. 13). Groundwater storage and responsiveness have been found to be important in determining drought duration and severity. In Austrian catchments, Van Loon and Laaha (2015) found that the mean duration of discharge droughts had a strong positive correlation with BFI, as was found in this study for clusters three and four (Fig. 13). Van Loon and Laaha (2015) also found that other catchment properties representative of catchment storage, such as aquifer depth and the presence of lakes and wetlands, had weak correlations with mean discharge drought duration. In the present study, stronger positive correlations were found between drought duration and the percentage of highly productive fractured rock and the percentage of the catchment with no gleyed soils. The weaker relationships in the Austrian study were thought, however, to be a result of missing data for some of the catchment properties, rather than a lack of influence (Van Loon and Laaha, 2015).

Laizé and Hannah (2010) found slope, BFIHOST (a measure of catchment responsiveness derived using the HOST (hydrology of soil types) classification; Boorman et al., 1995), percentage of arable land, elevation and bedrock permeability to significantly influence seasonal flows in UK Benchmark catchments. They classified catchments into upland impermeable, lowland permeable and lowland impermeable groups. In lowland permeable catchments, regional climate was a poorer predictor of streamflow due to the climate buffering provided by the permeable catchment. Chiverton et al. (2015a) found that BFIHOST, the percentage of highly productive fractured rock, the depth to the gleyed soil layer, the percentage of arable land, slope and PROPWET were all significant catchment properties influencing the temporal dependence of flows in UK Benchmark catchments. Temporal dependence can be thought of as indicative of the average lag between meteorological and hydrological signals; catchments in clusters one and two (three and four) showed less (more) temporal dependence in streamflow (Chiverton et al., 2015a). A similar pattern was found here in SPI- $n$, with shorter (longer) SPI accumulation periods being most strongly correlated in clusters one and two (clusters three and four).

Chiverton et al. (2015a) found the percentage of arable land to be the best catchment property to distinguish clusters based on the temporal dependence of streamflow. However, they argued that this was likely due to the positive relationship with the percentage of highly productive fractured rock and the negative relationship with other catchment properties such as high elevations and PROPWET. Arable land, in effect, characterises permeable, lowland well-drained catchments with high storage. In Austrian catchments, forest cover was positively, but weakly, correlated with both discharge drought mean duration and mean deficit (Van Loon and Laaha, 2015). In the present study, the percentage of woodland was significantly ( $\alpha=0.1$ ), although weakly, correlated with the percentage of no gleyed soils, BFI, the percentage of highly productive fractured rock and area $(r=-0.37,-0.37$, $-0.33,-0.28$, respectively). As such, it is more likely that the significant relationships between the percentage of woodland and hydrological drought characteristics are a result of the soil and geology types associated with the woodland land cover rather than the presence (or absence) of woodland itself.

\subsection{Implications for drought monitoring and early warning}

The SPI is widely used in existing drought M\&EW systems, but the SSI is less widely adopted (Bachmair et al., 2016). This may be a result of the poorer availability of streamflow data in comparison to precipitation data, especially at the short timescales involved in producing useful drought M \& EW products. However, the monitoring of hydrological variables and the incorporation of hydrological drought indices is beneficial for effective drought planning and management, and it is particularly useful for communication purposes if both precipitation and streamflow are monitored in a comparable way. In locations where streamflow data are available, the SSI can be used directly in drought M \& EW. While this is preferable, SPI could potentially provide a surrogate for hydrological impacts, provided appropriate response times are known.

The correlation results, Fig. 8, showing the spatial variability in SPI- $n$ (the accumulation period of SPI most strongly correlated with SSI-1), give an indication of accumulation periods that could stand as proxies for hydrological droughts in monthly precipitation data. This allows the more widely and rapidly available precipitation data to be used for identifying future potential hydrological droughts. The identification of these relationships could also allow estimation in areas where no streamflow data exist, based on precipitation data; the most suitable timescales for monitoring could be estimated based on widely available climate and catchment descriptors (in particular SAAR and BFIHOST which are avail- 
able at ungauged locations; Spackman, 1993; Boorman et al., 1995; Bayliss, 1999).

The results also highlight some of the problems with using the SPI and SSI when calculated for long accumulation periods for locations that have seen an increasing, or decreasing, long-term trend in precipitation or streamflow such as Scotland. Although being able to calculate SPI or SSI for any user-defined accumulation period makes the indicators more flexible, it is essential that meaningful accumulation periods should be chosen to capture the drought characteristics typical of current meteorological or hydrological conditions (Vicente-Serrano and López-Moreno, 2005). For example, the long, severe droughts shown in Scotland for both SPI and SSI for the 18-month accumulation period (Figs. 3 and 5) are not typical of the droughts that have been observed (Jones and Lister, 1998; Marsh et al., 2007). The short droughts that have been most influential for water resources in Scotland are better captured by shorter accumulation periods that are less confounded by the long-term increased precipitation and streamflow trends. Moreover, the findings reaffirm that accumulation periods should be chosen based on likely impacts; Bachmair et al. (2015) observed that short SPI accumulation periods are strongly linked to impacts in north-west Britain, while longer SPI accumulation periods trigger impacts in the south-east.

\subsection{Further research}

With the importance of groundwater, particularly in the south and east of England for water supply, to understand fully hydrological drought characteristics and propagation, it is necessary to include a groundwater component to the analysis. Furthermore, although catchment storage plays a key role in determining hydrological drought characteristics and propagation in the south and east, the seasonality and autocorrelation of streamflow, caused by evapotranspiration, will also be influential. Undertaking propagation analysis though the hydrological cycle, using the Standardised Precipitation Evapotranspiration Index (SPEI; Vicente-Serrano et al., 2010), the Standardised Streamflow Index (SSI; VicenteSerrano et al., 2012b; Lorenzo-Lacruz et al., 2013a) and the Standardised Groundwater Index (SGI; Bloomfield and Marchant, 2013) would therefore give a clearer picture of the climate and catchment properties influential on drought duration, severity and propagation, paving the way for more integrated drought $M \& E W$. In addition, the seasonal variability in drought propagation should be investigated. Studies in Spain found there were distinct differences between the duration of the SPI and SPEI accumulation period most strongly correlated with standardised monthly streamflow (SSI-1) depending on whether full time series or individual months were cross-correlated (Vicente-Serrano and López-Moreno, 2005; López-Moreno et al., 2013). The seasonal component is particularly important in the south and east of England, where summer streamflow and water resources are highly dependent on winter recharge.

The use of near-natural Benchmark catchments in this study has allowed the investigation of hydrological drought characteristics and propagation processes without results being confounded by artificial influences. However, it is often man-made systems that the human population is most reliant upon for water supply, agriculture, etc. Understanding these processes in catchments affected by anthropogenic activities is crucial for truly effective drought M \& EW systems. Further work on the drought and propagation characteristics in these modified systems will be much more challenging (Van Loon, 2015). It is likely that the combination of human activities, alongside natural catchment and climate characteristics, will produce more divergent results. However, the results from this study could be used to stratify catchments based on their climate and catchment properties when tackling the challenges of quantifying drought hazard in catchments with anthropogenic modifications.

Finally, as with most observation-based studies of drought, the brevity of available hydrological records is a constraint. The period of analysis (1961-2012) does not capture the full range of known hydrological variability, and previous studies have highlighted the importance of earlier droughts in the UK (Marsh et al., 2007). Longer records could influence the drought characteristics presented here, although the same regional picture and propagation characteristics would undoubtedly emerge. Similar methods to those used here will be applied in the future to longer records. Localised reconstructions of drought are becoming available (Lennard et al., 2016; Spraggs et al., 2015), while national-scale reconstruction research is in progress (e.g. Historic Droughts; http: //www.ceh.ac.uk/our-science/projects/historic-droughts).

\section{Conclusion}

Meteorological and hydrological drought characteristics and propagation behaviours of 121 near-natural UK catchments were analysed using SPI and SSI over a range of accumulation periods. Meteorological drought duration and severity characteristics showed little spatial variability, whilst hydrological drought characteristics showed many (few), short (long), less (more) severe events in the north and west (south and east) of the UK. Catchments underlain by aquifers tended to show more of a delay in the propagation of drought from meteorological to hydrological drought, with longer SPI accumulation periods most strongly correlated with SSI1. Standard-period average annual rainfall was found to be important for hydrological drought duration, severity and propagation in the north and west of the UK where catchment storage is generally low, whilst in the south and east, catchment storage and other catchment properties are more influential on hydrological drought duration, severity and propagation. The greater understanding of the UK drought hazard 
provided by this study can be used as a foundation for future developments of M \& EW in the UK, laying the foundations for better drought preparedness and increased resilience to drought.

\section{The Supplement related to this article is available online at doi:10.5194/hess-20-2483-2016-supplement.}

Acknowledgements. This study is an outcome of the Belmont Forum Project DrIVER (Drought Impacts: Vulnerability Thresholds in monitoring and Early warning Research). Financial support was provided by the UK Natural Environment Research Council (grant NE/L010038/1). We thank the UK National River Flow Archive (NRFA) for all streamflow and precipitation data, and both the NRFA and the British Geological Survey for catchment property data. The streamflow and precipitation data used here can be obtained from the NRFA on request, as can the majority of catchment properties. The authors would like to thank Sergio Vicente-Serrano, an anonymous reviewer and the editor, Jean-Philippe Vidal, for their constructive comments that helped improve the paper.

Edited by: J.-P. Vidal

\section{References}

Bachmair, S., Svensson, C., Hannaford, J., Barker, L. J., and Stahl, K.: A quantitative analysis to objectively appraise drought indicators and model drought impacts, Hydrol. Earth Syst. Sci. Discuss., 12, 9437-9488, doi:10.5194/hessd-12-9437-2015, 2015.

Bachmair, S., Stahl, K., Collins, K., Hannaford, J., Acreman, M., Svoboda, M., Knutson, C., Smith, K. H., Wall, N., Fuchs, B., Crossman, N. D., and Overton, I. C.: Drought indicators revisited: the need for a wider consideration of environment and society, WIREs Water, doi:10.1002/wat2.1154, online first, 2016.

Bayliss, A.: Flood estimation handbook volume 5: Catchment descriptors, Institute of Hydrology, Wallingford, Wallingford, UK, 1999.

Bloomfield, J. P. and Marchant, B. P.: Analysis of groundwater drought building on the standardised precipitation index approach, Hydrol. Earth Syst. Sci., 17, 4769-4787, doi:10.5194/hess-17-4769-2013, 2013.

Bloomfield, J. P., Allen, D., and Griffiths, K.: Examining geological controls on baseflow index (BFI) using regression analysis: An illustration from the Thames Basin, UK, J. Hydrol., 373, 164176, 2009.

Boorman, D. B., Hollis, J.M., and Lilly, A.: Hydrology of soil types: a hydrologically-based classification of the soils of United Kingdom, Institute of Hydrology, Wallingford, Wallingford, UK, IH Report no. 126, 146 pp., 1995.

Bradford, R. and Marsh, T.: Defining a network of benchmark catchments for the UK, Proc. ICE-Water Marit. Eng., 156, 109$116,2003$.
Chiverton, A., Hannaford, J., Holman, I., Corstanje, R., Prudhomme, C., Bloomfield, J., and Hess, T. M.: Which catchment characteristics control the temporal dependence structure of daily river flows?, Hydrol. Process., 29, 1353-1369, 2015 a.

Chiverton, A., Hannaford, J., Holman, I. P., Corstanje, R., Prudhomme, C., Hess, T. M., and Bloomfield, J. P.: Using variograms to detect and attribute hydrological change, Hydrol. Earth Syst. Sci., 19, 2395-2408, doi:10.5194/hess-19-2395-2015, 2015b.

Collins, K., Hannaford, J., Haines, S., Bachmair, S., Crossman, N., Stephens, L., and Svoboda, M.: Drought: understanding and reducing vulnerability through monitoring and early warning systems, Report of the DrIVER workshop, DrIVER Project Report, 17 March 2015, Wallingford, UK, 30 pp., 2015.

Dixon, H., Hannaford, J., and Fry, M. J.: The effective management of national hydrometric data: experiences from the United Kingdom, Hydrolog. Sci. J., 58, 1383-1399, 2013.

Dunn, P. K.: tweedie: Tweedie exponential family models, R package version 2.2.1, available at: https://cran.r-project.org/web/ packages/tweedie/index.html, last access: 6 June 2016, 2014.

Environment Agency: Water situation reports for England, https://www.gov.uk/government/collections/ water-situation-reports-for-england, last access: 31 March 2016.

Fleig, A. K., Tallaksen, L. M., Hisdal, H., and Hannah, D. M.: Regional hydrological drought in north-western Europe: linking a new Regional Drought Area Index with weather types, Hydrol Process., 25, 1163-1179, 2011.

Folland, C. K., Hannaford, J., Bloomfield, J. P., Kendon, M., Svensson, C., Marchant, B. P., Prior, J., and Wallace, E.: Multiannual droughts in the English Lowlands: a review of their characteristics and climate drivers in the winter half-year, Hydrol. Earth Syst. Sci., 19, 2353-2375, doi:10.5194/hess-19-23532015, 2015.

Gosling, R.: Assessing the impact of projected climate change on drought vulnerability in Scotland, Hydrol. Res., 45, 806-816, 2014.

Gudmundsson, L. and Stagge, J. H.: SCI: Standardized Climate Indices such as SPI, SRI or SPEI, R package version 1.0.1, available at: https://cran.r-project.org/web/packages/SCI/index.html, last access: 6 June 2016, 2014.

Gustard, A., Bullock, A., and Dixon, J. M.: Low flow estimation in the United Kingdom, Institute of Hydrology, Wallingford, UK, IH Report No. 108, 88 pp., 1992.

Guttman, N. B.: Accepting the standardized precipitation index: a calculation algorithm, J. Am. Water Resour. As., 35, 311-322, 1999.

Hannaford, J.: Climate-driven changes in UK river flows A review of the evidence, Prog. Phys. Geogr., 39, 29-48, 2015.

Hannaford, J. and Marsh, T.: An assessment of trends in UK runoff and low flows using a network of undisturbed catchments, Int. J. Climatol., 26, 1237-1253, 2006.

Hannaford, J., Lloyd-Hughes, B., Keef, C., Parry, S., and Prudhomme, C.: Examining the large-scale spatial coherence of European drought using regional indicators of precipitation and streamflow deficit, Hydrol. Process., 25, 1146-1162, doi:10.1002/hyp.7725, 2011.

Haslinger, K., Koffler, D., Schöner, W., and Laaha, G.: Exploring the link between meteorological drought and streamflow: Effects of climate-catchment interaction, Water Resour. Res., 50, 2468 2487, 2014. 
Hayes, M., Svoboda, M., Wall, N., and Widhalm, M.: The Lincoln declaration on drought indices: universal meteorological drought index recommended, B. Am. Meteorol. Soc., 92, 485-488, 2011.

Hidsal, H., Tallaksen, L. M., Clausen, B., Peters, E., and Gustard, A.: Hydrological Drought Characteristics, in: Developments in Water Science 48 Hydrological Drought, edited by: Tallaksen, L. M. and Van Lanen, H. A. J., Elsevier, Amsterdam, the Netherlands, 139-198, 2004.

Jones, P. and Lister, D.: Riverflow reconstructions for 15 catchments over England and Wales and an assessment of hydrologic drought since 1865, Int. J. Climatol., 18, 999-1013, 1998.

Jørgensen, B.: Exponential dispersion models, J. Roy. Stat. Soc. B, 49, 127-162, 1987.

Kay, A., Bell, V., Blyth, E., Crooks, S., Davies, H., and Reynard, N.: A hydrological perspective on evaporation: historical trends and future projections in Britain, J. Water Clim. Change, 4, 193-208, 2013.

Kumar, R., Musuuza, J. L., Van Loon, A. F., Teuling, A. J., Barthel, R., Ten Broek, J., Mai, J., Samaniego, L., and Attinger, S.: Multiscale evaluation of the Standardized Precipitation Index as a groundwater drought indicator, Hydrol. Earth Syst. Sci., 20, 1117-1131, doi:10.5194/hess-20-1117-2016, 2016.

Laizé, C. L. and Hannah, D. M.: Modification of climate-river flow associations by basin properties, J. Hydrol., 389, 186-204, 2010.

Lennard, A. T., Macdonald, N., Clark, S., and Hooke, J. M.: The application of a drought reconstruction in water resource management, Hydrol. Res., doi:10.2166/nh.2015.090, online first, 2016.

Lloyd-Hughes, B.: The impracticality of a universal drought definition, Theor. Appl. Climatol., 117, 607-611, 2014.

Lloyd-Hughes, B. and Saunders, M. A.: A drought climatology for Europe, Int. J. Climatol., 22, 1571-1592, 2002.

López-Moreno, J. I., Vicente-Serrano, S. M., Zabalza, J., Beguería, S., Lorenzo-Lacruz, J., Azorin-Molina, C., and Morán-Tejeda, E.: Hydrological response to climate variability at different time scales: A study in the Ebro basin, J. Hydrol., 477, 175-188, doi:10.1016/j.jhydrol.2012.11.028, 2013.

Lorenzo-Lacruz, J., Morán-Tejeda, E., Vicente-Serrano, S. M., and López-Moreno, J. I.: Streamflow droughts in the Iberian Peninsula between 1945 and 2005: spatial and temporal patterns, Hydrol. Earth Syst. Sci., 17, 119-134, doi:10.5194/hess-17-1192013, 2013a.

Lorenzo-Lacruz, J., Vicente-Serrano, S. M., González-Hidalgo, J. C., López-Moreno, J. I., and Cortesi, N.: Hydrological drought response to meteorological drought in the Iberian Peninsula, Clim. Res., 58, 117-131, 2013b.

Marsh, T. and Hannaford, J.: UK hydrometric register, Hydrological data UK series, Centre for Ecology and Hydrology, Wallingford, UK, 200 pp., 2008.

Marsh, T., Cole, G., and Wilby, R.: Major droughts in England and Wales, 1800-2006, Weather, 62, 87-93, 2007.

McCabe, G. J., Palecki, M. A., and Betancourt, J. L.: Pacific and Atlantic Ocean influences on multidecadal drought frequency in the United States, P. Natl. Acad. Sci. USA, 101, 4136-4141, 2004.

McKee, T. B., Doesken, N. J., and Kleist, J.: The relationship of drought frequency and duration to time scales, Proceedings of the 8th Conference on Applied Climatology, 17-22 January 1993, Anaheim, California, 179-183, 1993.

Met Office: Quality control of rainfall observations, Met Office, Bracknell, UK, Met Office Observations Supply, 4 pp., 2001.
Morris, D. G. and Flavin, R. W.: A digital terrain model for hydrology, Proceedings of the 4th International Symposium on Spatial Data Handling, International Geographical Union, Zurich, 250262, 1990.

Núñez, J., Rivera, D., Oyarzún, R., and Arumí, J.: On the use of Standardized Drought Indices under decadal climate variability: Critical assessment and drought policy implications, J. Hydrol., 517, 458-470, 2014.

Pyper, B. J. and Peterman, R. M.: Comparison of methods to account for autocorrelation in correlation analyses of fish data, Can. J. Fish. Aquat. Sci., 55, 2127-2140, 1998.

Rahiz, M. and New, M.: Spatial coherence of meteorological droughts in the UK since 1914, Area, 44, 400-410, doi:10.1111/j.1475-4762.2012.01131.x, 2012.

Sheffield, J. and Wood, E. F.: Drought: Past problems and future scenarios, Earthscan, London, 210 pp., 2011.

Southern Water: Drought Plan, https://www.southernwater.co.uk/ Media/Default/PDFs/finalDroughtPlanFeb13_mainRept.pdf, last access: 31 March 2016.

Spackman, E.: Calculation and Mapping of Rainfall Averages for 1961-90, British Hydrology Society Meeting on Areal Rainfall, 15 December 1993, University of Salford, Manchester, 1993.

Spraggs, G., Peaver, L., Jones, P., and Ede, P.: Re-construction of historic drought in the Anglian Region (UK) over the period 1798-2010 and the implications for water resources and drought management, J. Hydrol., 526, 231-252, doi:10.1016/j.jhydrol.2015.01.015, 2015.

Stagge, J. H., Tallaksen, L. M., Gudmundsson, L., Van Loon, A. F., and Stahl, K.: Candidate distributions for climatological drought indices (SPI and SPEI), Int. J. Climatol., 35, 4027-4040, 2015.

Svensson, C.: Seasonal river flow forecasts for the United Kingdom using persistence and historical analogues, Hydrolog. Sci. J., 61, 19-35, doi:10.1080/02626667.2014.992788, 2016.

Svensson, C., Brookshaw, A., Scaife, A., Bell, V., Mackay, J., Jackson, C., Hannaford, J., Davies, H., Arribas, A., and Stanley, S.: Long-range forecasts of UK winter hydrology, Environ. Res. Lett., 10, 064006, doi:10.1088/1748-9326/10/6/064006, 2015a.

Svensson, C., Hannaford, J., and Prosdocimi, I.: Statistical distributions for monthly aggregations of precipitation and streamflow in drought indicator applications, Water Resour. Res., submitted, 2016.

Tanguy, M., Svensson, C., Hannaford, J., and Fry, M.: CEH-SPI: a drought indicator dataset for the UK, Environ. Sci. Data, in preparation, 2016.

Thames Water: Final Drought Plan, http://www.thameswater.co.uk/ tw/common/downloads/aboutus-drought-plan/Thames_Water_ Final_Drought_Plan_2013.pdf, last access: 12 April 2016.

Tijdeman, E., Bachmair, S., and Stahl, K.: Controls on hydrologic drought duration in near-natural streamflow in Europe and the USA, Hydrol. Earth Syst. Sci. Discuss., 12, 12877-12910, doi:10.5194/hessd-12-12877-2015, 2015.

Tweedie, M. C. K.: An index which distinguishes between some important exponential families, in: Statistics: Applications and New Directions, Proceedings of the Indian Statistical Institute Golden Jubilee International Conference, 16-19 December 1981, Calcutta, India, edited by: Ghosh, J. K. and Roy, J., Indian Statistical Institute, Calcutta, India, 579-604, 1981.

Van Lanen, H. A. J., Wanders, N., Tallaksen, L. M., and Van Loon, A. F.: Hydrological drought across the world: impact of climate 
and physical catchment structure, Hydrol. Earth Syst. Sci., 17, 1715-1732, doi:10.5194/hess-17-1715-2013, 2013.

Van Loon, A. F.: Hydrological drought explained, Wiley Interdisciplinary Reviews: Water, 2, 359-392, 2015.

Van Loon, A. F. and Laaha, G.: Hydrological drought severity explained by climate and catchment characteristics, J. Hydrol., 526, 3-14, 2015.

Van Loon, A. F. and Van Lanen, H. A. J.: A process-based typology of hydrological drought, Hydrol. Earth Syst. Sci., 16, 19151946, doi:10.5194/hess-16-1915-2012, 2012.

Vicente-Serrano, S. M.: Differences in spatial patterns of drought on different time scales: an analysis of the Iberian Peninsula, Water Resour. Manage., 20, 37-60, doi:10.1007/s11269-006-29748, 2006.

Vicente-Serrano, S. M. and López-Moreno, J. I.: Hydrological response to different time scales of climatological drought: an evaluation of the Standardized Precipitation Index in a mountainous Mediterranean basin, Hydrol. Earth Syst. Sci., 9, 523-533, doi:10.5194/hess-9-523-2005, 2005.

Vicente-Serrano, S. M., González-Hidalgo, J. C., de Luis, M., and Raventós, J.: Drought patterns in the Mediterranean area: the Valencia region (eastern Spain), Clim. Res., 26, 5-15, 2004.

Vicente-Serrano, S. M., Beguería, S., and López-Moreno, J. I.: A multiscalar drought index sensitive to global warming: the standardized precipitation evapotranspiration index, J. Climate, 23, 1696-1718, 2010.
Vicente-Serrano, S. M., Beguería, S., Lorenzo-Lacruz, J., Camarero, J. J., López-Moreno, J. I., Azorin-Molina, C., Revuelto, J., Morán-Tejeda, E., and Sanchez-Lorenzo, A.: Performance of drought indices for ecological, agricultural, and hydrological applications, Earth Interact., 16, 1-27, 2012a.

Vicente-Serrano, S. M., López-Moreno, J. I., Beguería, S., LorenzoLacruz, J., Azorin-Molina, C., and Morán-Tejeda, E.: Accurate computation of a streamflow drought index, J. Hydrol. Eng., 17, 318-332, 2012b.

Vidal, J.-P., Martin, E., Franchistéguy, L., Habets, F., Soubeyroux, J.-M., Blanchard, M., and Baillon, M.: Multilevel and multiscale drought reanalysis over France with the Safran-Isba-Modcou hydrometeorological suite, Hydrol. Earth Syst. Sci., 14, 459-478, doi:10.5194/hess-14-459-2010, 2010.

Watts, G., von Christierson, B., Hannaford, J., and Lonsdale, K.: Testing the resilience of water supply systems to long droughts, J. Hydrol., 414, 255-267, 2012.

Wilhite, D. A. and Glantz, M. H.: Understanding: the drought phenomenon: the role of definitions, Water Int., 10, 111-120, 1985.

Wilhite, D. A., Hayes, M. J., Knutson, C., and Smith, K. H.: Planning for drought: Moving from crisis to risk management, J. Am. Water Resour. As., 36, 697-710, 2000.

Wu, H., Svoboda, M. D., Hayes, M. J., Wilhite, D. A., and Wen, F.: Appropriate application of the standardized precipitation index in arid locations and dry seasons, Int. J. Climatol., 27, 65-79, doi:10.1002/joc.1371, 2007. 